\title{
Wind-driven decadal sea surface height and main pycnocline depth changes in the western subarctic North Pacific
}

\author{
Akira Nagano ${ }^{1 *}$ (D) and Masahide Wakita ${ }^{2}$
}

\begin{abstract}
The northward shrinkage of the North Pacific western subarctic gyre (WSAG) in the early 2000s is associated with a sea surface height (SSH) elevation and is correlated to sea surface wind stress change. By using a Rossby wave model forced by wind stress, which computes the component variations due to the barotropic and first to fourth baroclinic modes, we estimated decadal changes in SSH and main pycnocline depth in the subpolar region. Realistic decadal SSH elevation and deepening of the main pycnocline depth associated with the northward shrinkage of the western subarctic gyre from the late 1990s to the mid-2000s were reproduced by the model. The sea surface elevation was caused primarily by the barotropic Rossby wave response to the relaxation of the Ekman suction due to the attenuation of the Aleutian Low by frequent La Niña occurrences after the late 1990s in addition to the long-term weakening of the westerly wind. The northward shrinkage of the WSAG was found to be associated with the intensification of an anticyclonic circulation centered around $43-44^{\circ} \mathrm{N}, 170-175^{\circ} \mathrm{E}$. The westerly wind weakening deepened the main pycnocline in the western subarctic region through the baroclinic Rossby wave mode response to the wind stress change, which mostly accounts the equivalent halocline deepening at station $\mathrm{K} 2\left(47^{\circ} \mathrm{N}, 160^{\circ} \mathrm{E}\right)$. While the first baroclinic mode variation of the water density significantly attenuates during propagation, the higher mode variations, particularly the second and third mode variations, are locally excited through a quasi-resonant amplification mechanism and have profound impacts on the depth of the upper main pycnocline.
\end{abstract}

Keywords: North Pacific western subarctic gyre, Aleutian Low, SSH, Barotropic and baroclinic Rossby waves, Wind stress

\section{Introduction}

In the subpolar North Pacific, a basin-scale cyclonic circulation, called the subpolar gyre, is driven by the sea surface wind stress over the entire subpolar ocean (Dodimead et al. 1963; Ohtani 1973; Favorite et al. 1976; Nagata et al. 1992). The western boundary current of the subpolar gyre flows southwestward along the eastern coast of the Kamchatka Peninsula as the East Kamchatka Current and east of the Kuril Islands and Hokkaido as the Oyashio Current. It returns to the central subpolar region as an interior weak flow. The southern border of the subpolar gyre, i.e., the Oyashio Current, was reported to have migrated

\footnotetext{
*Correspondence: nagano@jamstec.go.jp

${ }^{1}$ Research Institute for Global Change, Japan Agency for Marine-Earth Science and Technology (JAMSTEC), 2-15 Natsushima-cho, Yokosuka Kanagawa 237-0061, Japan

Full list of author information is available at the end of the article
}

northward from the 1990s to the 2000s, an event suggested to have been caused by a change in the wind stress curl field (Kuroda et al. 2015). Wind-driven meridional shifts in the Oyashio Current have also been suggested by Sekine (1999) and others.

The subpolar gyre is known to have regional cyclonic circulations in its interior (Dodimead et al. 1963; Ohtani 1973; Favorite et al. 1976; Nagata et al. 1992). A regional cyclonic circulation, called the western subarctic gyre (WSAG), is embedded in the western part of the subpolar gyre, as schematically illustrated in Fig. 1 . The southwestward current of the western border of the WSAG merges into the East Kamchatka Current. Due to the moderate baroclinic structures of the current and density in the WSAG, the main pycnocline (halocline) becomes shallower toward the center of the gyre (Miura et al. 2002), 


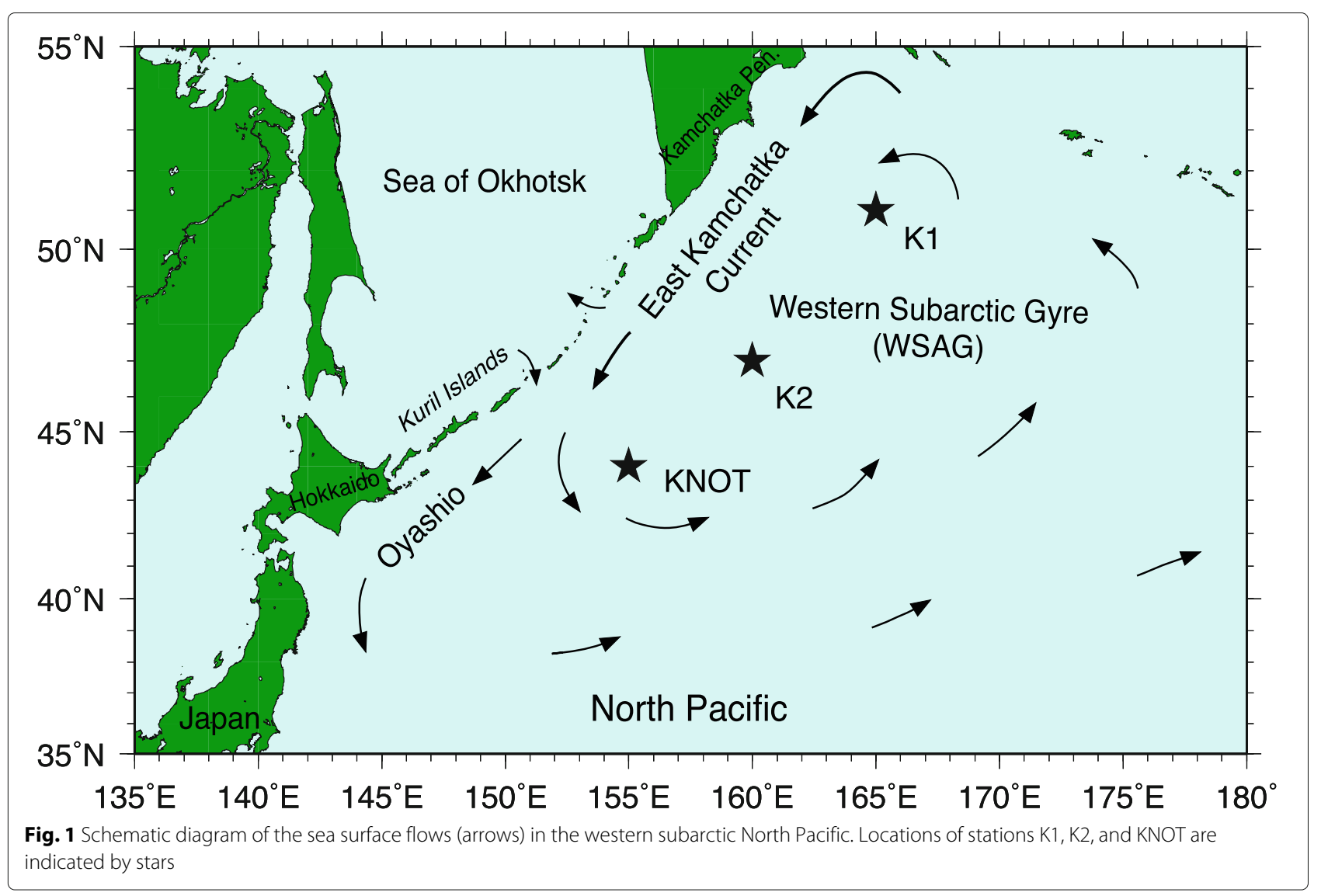

where the sea surface height ( $\mathrm{SSH}$ ) is observed to be minimal (Nagano et al. 2016).

In the western subarctic region, a temperature minimum layer, called the dichothermal layer, exists at a depth between $100 \mathrm{~m}$ and $200 \mathrm{~m}$ above the main pycnocline or halocline (Dodimead et al. 1963; Favorite et al. 1976). The dichothermal layer is occupied by the remnant of the winter mixed layer water formed during the previous winter (Miura et al. 2002; Wakita et al. 2010, 2013). In the late 1990s, hydrographic and chemical time series observations in the western subarctic region were initiated at stations $\mathrm{K} 2\left(47^{\circ} \mathrm{N}, 160^{\circ} \mathrm{E}\right)$ and $\mathrm{KNOT}\left(44^{\circ} \mathrm{N}, 155^{\circ} \mathrm{E}\right)$ (Fig. 1). Using observation longer than 15 years, a decadal deepening of the halocline was revealed at these sites; in this layer, slow acidification and decreasing carbon dioxide release to the atmosphere in the winter were observed (Wakita et al. 2010, 2013, 2017).

Nagano et al. (2016) found that the WSAG shrank northward from the late 1990s to the mid-2000s on the basis of altimetric SSH during the period of 1992-2010. The increase in $\mathrm{SSH}$ in the western subarctic region due to the gyre change until 2000 was also monitored by Qiu (2002). Combining conductivity-temperature-depth (CTD) and SSH data using the altimetry-based gravest empirical mode (AGEM) method, (Nagano et al. 2016) estimated the change in the halocline or upper main pycnocline depth. As a result, the halocline at K2 was found to be displaced downward in association with the northward shrinkage of the WSAG; further, it is related to the decadal decrease in water density in the dichothermal layer, i.e., the base of the winter mixed layer at $\mathrm{K} 2$. In other words, water density in the dichothermal layer is substantially controlled by the WSAG via the change in the upper main pycnocline depth. We consider that barotropic variations, not affecting density in the subsurface layer, are included in the subarctic decadal SSH change. However, the AGEM method of Nagano et al. (2016) does not distinguish the barotropic variations from baroclinic ones, which are possibly related to the observed decadal density change. Another method that treats separately barotropic and baroclinic variations is required to examine the mechanism of the upper main pycnocline change.

Over the subpolar North Pacific, there are vigorous variations of the Aleutian Low and the westerly wind (e.g., Wallace and Gutzler 1981), which mainly drives the subpolar gyre. Isoguchi and Kawamura (2006) reported that seasonal to interannual variations in coastal sea level and 
SSH in the Oyashio and East Kamchatka Current regions are generated by the wind stress changes. The decadal gyre variations in the western subarctic region might be driven by changes in wind stress induced by those of the westerly wind and the Aleutian Low. The northward shrinkage of the WSAG, indicated by the time coefficient of the first empirical orthogonal function mode of SSH (Nagano et al. 2016), is found to be simultaneously linked to the changes in wind stress curl in the eastern subpolar region and the region southeast of the Kamchatka Peninsula, as implied by fairly high correlation in Fig. 2. Meanwhile, note that there is no significant trend in the annual mean potential density of the sea surface water at K2 (Wakita et al. 2017). Therefore, the decadal elevation in SSH and deepening of the halocline depth at the station are not mainly attributable to changes in water density due to thermal expansion and freshwater supply in the sea surface layer.

Using a $\beta$-plane two-layer model forced by wind stress, Qiu (2002) suggested that the change in the WSAG is expected to be driven by the change in wind stress, although this has not been fully examined by past investigators. Under the assumption of the Sverdrup balance in the interior region of the subpolar gyre, variations in the gyre volume transport and SSH excited by interannual to decadal changes in wind stress such as due to the Pacific Decadal Oscillation (PDO) (Mantua et al. 1997; Mantua and Hare 2002) were examined by Isoguchi et al. (1997), Ishi and Hanawa (2005), and Isoguchi and Kawamura (2006). These simple models, in which neither the bottom topography (e.g., Ripa 1978) nor the beta-dispersion (e.g., Schopf et al. 1981) were not taken into account, reproduced reasonable decadal gyre changes. In other words, decadal fluctuations in the subpolar region are well explained by long Rossby wave responses to wind stress changes. However, these low-vertical-resolution models are insufficient to examine the observed potential density change associated with the northward shrinkage of the WSAG reported by Wakita et al. $(2010,2013,2017)$ and Nagano et al. (2016). A continuously stratified model is required to discuss the wind-driven density change in the western subarctic region.

In general, Rossby wave adjustments of the oceans to changes in wind stress are involved in the wind-driven changes of the circulations (e.g., LeBlond and Mysak 1978; Gill 1982; Pedlosky 1987). SSH changes accompanied by Rossby wave adjustments propagate westward with various speeds according to their spatial and temporal scales and are subject to eddy dissipation. Kawabe (2000, 2001) solved the vorticity gradient equation (e.g., LeBlond and Mysak 1978) with wind stress forcing to take into account the propagations of disturbances by Rossby waves and calculated interannual sea level variations at tide gauge stations in the North Pacific subtropical region. Adopting this method to the SSH changes in the North Pacific subpolar region, we can compute the changes in SSH and water potential density due to the individual barotropic and baroclinic mode changes excited by the wind stress changes. Moreover, we can examine the mechanism controlling how the WSAG shrinkage and main pycnocline deepening are caused by changes in wind stress.

In this study, we calculated variations in $\mathrm{SSH}$, volume transport, and water potential density using a dynamical model of barotropic and baroclinic Rossby waves excited by changes in wind stress including vertical and horizontal eddy dissipation. We examined whether the wind-driven $\mathrm{SSH}$ calculation produces the decadal SSH change associated with the northward WSAG shrinkage.

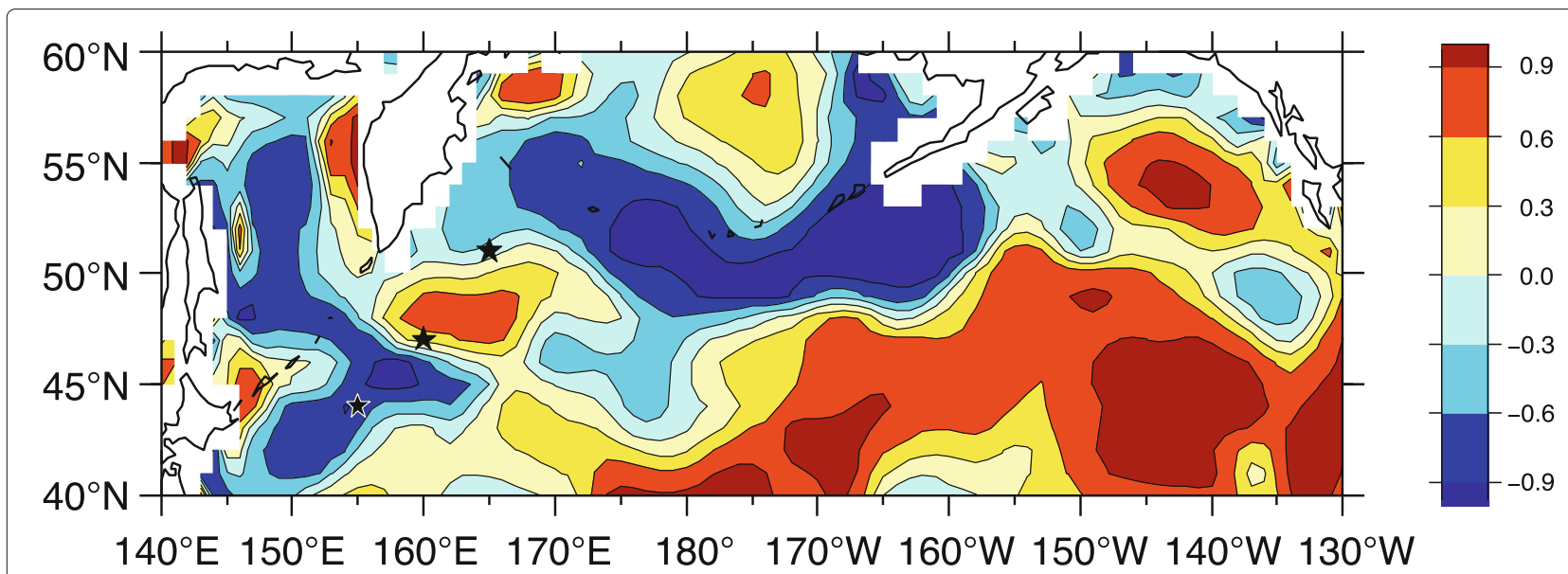

Fig. 2 Map of correlation coefficient between wind stress curl and the time coefficient of the first empirical orthogonal function mode of SSH calculated by Nagano et al. (2016). For the calculation, we used wind stress data provided by the US National Centers for Environmental Prediction/National Center for Atmospheric Research (NCEP/NCAR). Locations of stations K1, K2, and KNOT are indicated by stars 
Using the calculated SSH and potential density variations, we identified disturbances that yield the northward gyre shrinkage and discuss the mechanism of the decadal deepening of the main pycnocline at $\mathrm{K} 2$. The data and calculation method are described in "Materials/method" section. In "Results and discussion" section, we determine the parameters required for the $\mathrm{SSH}$ calculation comparing between the observed and calculated $\mathrm{SSH}$ changes at K2, using the obtained parameters, we calculate the SSH changes and describe their characteristics, and discuss the potential density change at K2. A summary and conclusion are provided in "Conclusions" section.

\section{Materials/method \\ SSH data}

Daily SSH anomalies with horizontal grid intervals of $1 / 4^{\circ}$ from January 1993 to December 2014 in the region of 40$60^{\circ} \mathrm{N}, 140^{\circ} \mathrm{E}-130^{\circ} \mathrm{W}$ were collected from the Archiving, Validation and Interpretation of Satellite Oceanographic (AVISO) delayed-time updated mapped data (DT-MSLAH, http://www.aviso.altimetry.fr/duacs/) (AVISO 2016). We calculated the monthly mean SSH anomalies, added them to the mean dynamic topography (MDT_CNESCLS13) compiled by Rio et al. (2011), and obtained the monthly absolute SSH. To analyze interannual to decadal variations in $\mathrm{SSH}$, we smoothed them using a 15-month running mean filter. The $\mathrm{SSH}$ data at $\mathrm{K} 1\left(51^{\circ} \mathrm{N}, 165^{\circ} \mathrm{E}\right)$, $\mathrm{K} 2$, and KNOT were obtained from the smoothed SSH data at the nearest grids.

\section{Wind stress data}

To compute wind-derived SSH variations, we used the monthly mean momentum flux vector, $\boldsymbol{\tau}=\left(\tau^{x}, \tau^{y}\right)$, where $\tau^{x}$ and $\tau^{y}$ are the zonal and meridional wind stresses, respectively, with horizontal grid intervals of $1^{\circ}$ in the region of $40-54^{\circ} \mathrm{N}, 160^{\circ} \mathrm{E}-135^{\circ} \mathrm{W}$ (the region enclosed by a black square in Fig. 3) from January 1979 to December 2014. The data were provided by the US National Centers for Environmental Prediction/National Center for Atmospheric Research (NCEP/NCAR) (Kalnay et al. 1996). From the $\tau$ data, we computed the Ekman pumping velocity $\left(w_{\mathrm{E}}=\nabla \times \boldsymbol{\tau} / f=\partial_{x}\left(\tau^{y} / f\right)-\partial_{y}\left(\tau^{x} / f\right)\right.$, where $f$ is the Coriolis parameter). Upward Ekman vertical velocity was taken to be positive $w_{\mathrm{E}}$. Namely, positive $w_{\mathrm{E}}$ indicates Ekman suction. To analyze interannual to decadal variations, we smoothed the $w_{\mathrm{E}}$ data using a 15month running mean filter. Using the smoothed $w_{\mathrm{E}}$ data, we calculated the SSH variations, as will be described in "Results and discussion" section.

\section{Hydrographic data}

Full-depth CTD data collected at the World Ocean Circulation Experiment (WOCE) P01 $\left(47^{\circ} \mathrm{N}\right)$ line from May 21 to June 13, 1999, by Watanabe et al. (2001) and Fukasawa et al. (2004) and others on board the R/V Kaiyo-maru (Japan Fisheries Agency) were used to estimate the vertical structures of the baroclinic Rossby wave modes. The CTD sensors were calibrated before and after the cruise. Water sampling at the CTD stations was performed using Niskin bottles mounted on the CTD

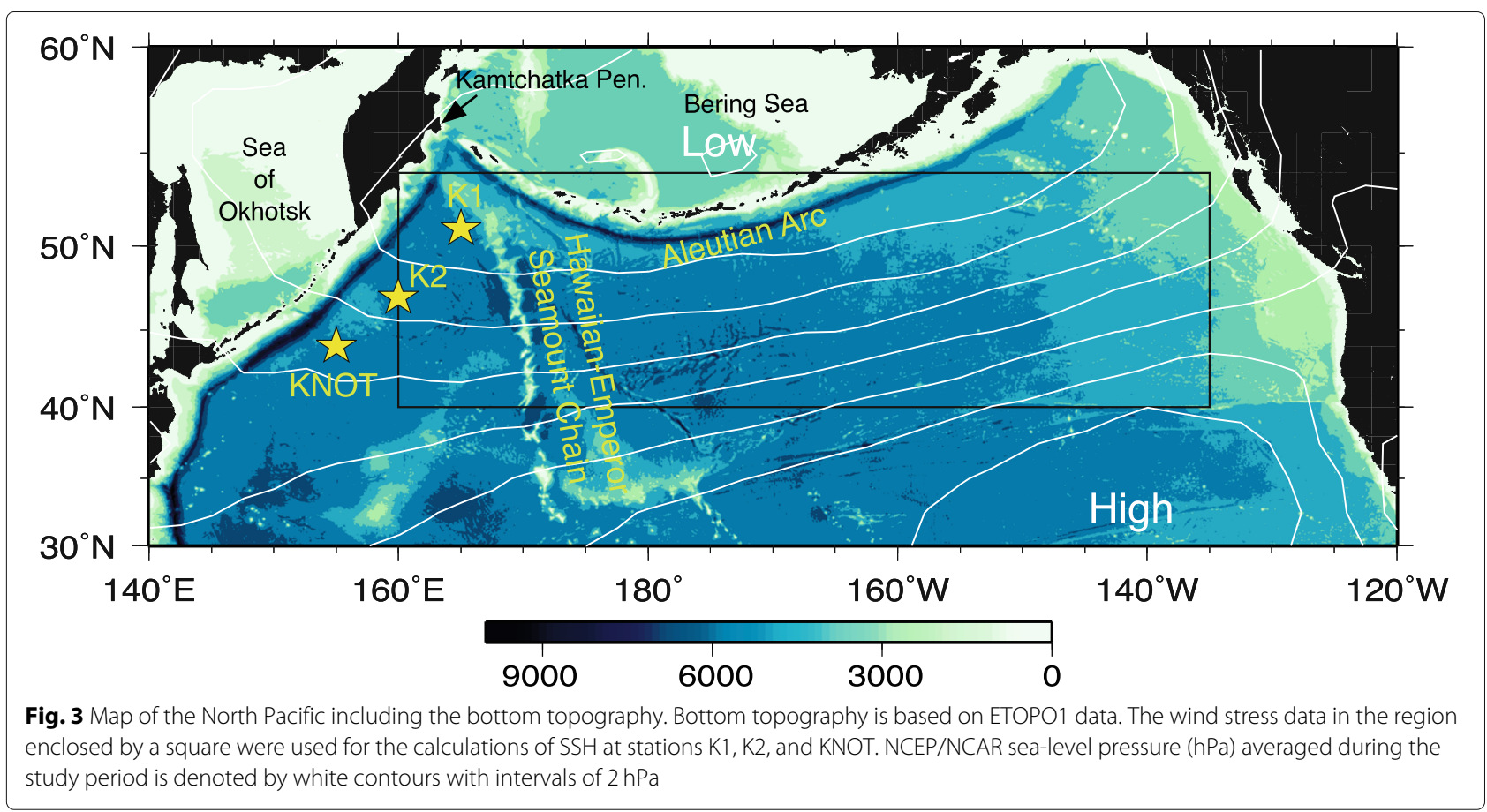


frame. By using the sampling data, the CTD data were calibrated. The accuracies of the temperature and salinity data used in this study are better than $0.00008{ }^{\circ} \mathrm{C}$ and 0.003 (psu), respectively. The zonally averaged profile of the potential density of seawater based on the CTD data collected in the western subarctic region between $160^{\circ} \mathrm{E}$ and $170^{\circ} \mathrm{E}$ were vertically averaged over $10 \mathrm{dbar}$ to eliminate small-scale vertical variations and gridded from $10 \mathrm{dbar}$ to $4000 \mathrm{dbar}$ at intervals of $10 \mathrm{dbar}$. In addition, we used a climatological potential density profile around K2 based on the World Ocean Database 2013 (WOD2013) (Boyer et al. 2013) to examined the validity of the use of WOCE P01 data collected in such a short time for the calculation of the vertical structures of the baroclinic modes.

\section{Model description and calculation procedure}

We adopted the $\beta$-plane linearized form of the hydrostatically balanced equations of motion and continuity to estimate the interannual to decadal variations in $\mathrm{SSH}(\eta)$ due to Rossby waves forced by changes in wind stress, as applied by Kawabe $(2000,2001)$ in the subtropical region of the North Pacific. Over a flat bottom ocean, perturbations of horizontal current velocity vector $\boldsymbol{u}=(u, v)$, pressure $p$, and water density $\rho$ are solved via separation of variables as follows:

$$
\begin{aligned}
& (\boldsymbol{u}, p)=\sum_{n=0}^{\infty}\left[\boldsymbol{u}_{n}(t, x, y), p_{n}(t, x, y)\right] \phi_{n}(z), \\
& \rho=\sum_{n=0}^{\infty} \rho_{n}(t, x, y) h_{n} \frac{\mathrm{d} \phi_{n}}{\mathrm{~d} z},
\end{aligned}
$$

where $t$ is time and $x, y$, and $z$ are the eastward, northward, and upward coordinates, respectively. The $\phi_{n}$ function is the $n$th eigenfunction, satisfying

$$
\frac{\mathrm{d}}{\mathrm{d} z}\left(\frac{1}{N^{2}} \frac{\mathrm{d} \phi_{n}}{\mathrm{~d} z}\right)+\frac{1}{C_{n}^{2}} \phi_{n}=0,
$$

where $C_{n}^{2}=g h_{n}, g$ is the gravitational acceleration $\left(9.80 \mathrm{~ms}^{-2}\right), h_{n}$ is the equivalent depth, $N^{2}=$ $-g \bar{\rho}^{-1} \partial \bar{\rho} / \partial z$ is the squared Brunt-Väisälä frequency, and $\bar{\rho}$ is the mean vertical profile of potential density. The eigenfunctions are normalized as

$$
\frac{1}{D_{\mathrm{b}}} \int_{-D_{\mathrm{b}}}^{0} \phi_{m} \phi_{n} \mathrm{~d} z= \begin{cases}1 & (m=n) \\ 0 & (m \neq n),\end{cases}
$$

where $D_{\mathrm{b}}$ is a constant bottom depth. Therefore, the vertical structure of the $n$th baroclinic Rossby wave mode, i.e., $\phi_{n}(n=1,2, \cdots, \infty)$, is obtained as the $n$th eigenfunction of Eq. (3) with the boundary condition of no vertical velocity, i.e., $\mathrm{d} \phi_{n} / \mathrm{d} z=0$, at the sea surface and bottom, i.e., $z=0$ and $-D_{\mathrm{b}}$. The barotropic Rossby wave mode is represented by the zeroth mode $(n=0)$ of $C_{0}^{2}=g D_{\mathrm{b}}$ and vertically constant $\phi_{0}$.

The governing equation of the meridional velocity perturbation due to the $n$th baroclinic mode of the Rossby waves, i.e., $v_{n}$, which is called the vorticity gradient equation (e.g., LeBlond and Mysak 1978), forced by interannual to decadal variations in wind stress is obtained in Cartesian coordinates as

$$
\begin{aligned}
f^{2} \frac{\partial v_{n}}{\partial t}-C_{n}^{2} \frac{\partial}{\partial t} \nabla^{2} v_{n}-C_{n}^{2} \beta \frac{\partial v_{n}}{\partial x} & =\frac{C_{n}^{2}}{D} \phi_{n}(0)\left(\frac{\partial^{2} w_{\mathrm{E}}}{\partial t \partial y}-f \frac{\partial w_{\mathrm{E}}}{\partial x}\right) \\
& +\left(A_{\mathrm{V}} N^{2}-A_{\mathrm{H}} C_{n}^{2} \nabla^{2}\right) \nabla^{2} v_{n}(5) \\
& -\left(K_{\mathrm{V}} N^{2}-K_{\mathrm{H}} C_{n}^{2} \nabla^{2}\right) \frac{f^{2}}{C_{n}^{2}} v_{n}
\end{aligned}
$$

where $\nabla^{2}=\partial_{x}^{2}+\partial_{y}^{2}, A_{\mathrm{H}}\left(A_{\mathrm{V}}\right)$ and $K_{\mathrm{H}}\left(K_{\mathrm{V}}\right)$ are the horizontal (vertical) eddy viscosity and diffusion coefficients, respectively, and $\beta$ is the latitudinal variation of $f$ (i.e., $f=f_{0}+\beta y$ ). The first, second, and third terms of the right hand side of Eq. (5) represent external forcing, eddy viscosity, and eddy dissipation, respectively. We assume $A_{\mathrm{V}}=K_{\mathrm{V}}\left(\equiv D_{\mathrm{V}}\right)$ and $A_{\mathrm{H}}=K_{\mathrm{H}}\left(\equiv D_{\mathrm{H}}\right)$ hereafter. Further, we define $B \equiv D_{\mathrm{V}} N^{2}$ and take to be constant, following to the presumption of $K_{\mathrm{V}} \propto N^{-2}$ in the western subarctic region by Andreev et al. (2002).

A single fluctuation of the Ekman pumping velocity, $w_{\mathrm{E}}$, is represented by a sustained forcing of superposed sinusoidal meridional modes as

$$
w_{\mathrm{E}}(t, x, y)=\sum_{m=1}^{\infty} W_{m} \sin \left(\frac{m \pi}{L} y\right) H\left(t-t_{0}\right) \delta\left(x-x_{0}\right),(6)
$$

where $W_{m}$ is amplitude of the $m$ th meridional mode of $w_{\mathrm{E}}, H$ is the Heaviside step function (defined as a function providing zero until time $t=t_{0}$ and unity afterward), $\delta$ is the Dirac delta function (defined as a function providing zero for any $x$ except for longitude $x=x_{0}$ ), and $L$ is the meridional length of the study region. $t_{0}$ and $x_{0}$ are time and the zonal position of the induction of $w_{\mathrm{E}}$, respectively, so that values of $W_{m}$ are determined for every $t_{0}$ and every $x_{0} . \partial^{2} w_{E} / \partial t \partial y$ in Eq. (5) is neglected because this term is not significantly effective due to its attribution to a zonal and temporal $\delta$ function.

Substituting Eq. (6) and the geostrophic relationship, $\rho_{0} f_{0} v_{n}=\partial_{x} p_{n}$, into Eq. (5), neglecting $\partial_{t} \partial_{y} w_{\mathrm{E}}$, and integrating with respect to $x$, we obtain

$$
\begin{array}{r}
{\left[f^{2} \frac{\partial}{\partial t}-C_{n}^{2} \frac{\partial}{\partial t} \nabla^{2}-C_{n}^{2} \beta \frac{\partial}{\partial x}+\left(\frac{f^{2}}{C_{n}^{2}}-\nabla^{2}\right)\left(B-D_{\mathrm{H}} C_{n}^{2} \nabla^{2}\right)\right] p_{n}} \\
=\frac{\rho_{0} f^{2} C_{n}^{2}}{D} \phi_{n}(0) \sum_{m=1}^{\infty} W_{m} \sin \left(\frac{m \pi}{L} y\right) H\left(t-t_{0}\right) \delta\left(x-x_{0}\right),
\end{array}
$$

where $\rho_{0}$ is the constant overall water density. 
The solution of Eq. (7) is found as

$$
\begin{aligned}
p_{n} & =\frac{\rho_{0} f^{2}}{\beta D} \phi_{n}(0) \sum_{m=1}^{\infty} W_{m} \sin \left(\frac{m \pi}{L} y\right) \cdot\left\{H\left(x-x_{0}\right)\right. \\
& \left.-\exp \left[-r_{m n}\left(t-t_{0}\right)\right] H\left[x-x_{0}+c_{m n}\left(t-t_{0}\right)\right]\right\},
\end{aligned}
$$

where

$$
\begin{aligned}
& c_{m n}=\beta C_{n}^{2} F_{m n}^{-1}, \\
& r_{m n}=\left[B+D_{\mathrm{H}} C_{n}^{2}\left(\kappa^{2}+\frac{m^{2} \pi^{2}}{L^{2}}\right)\right]\left(\kappa^{2}+\frac{m^{2} \pi^{2}}{L^{2}}+\frac{f^{2}}{C_{n}^{2}}\right) F_{m n}^{-1}, \\
& F_{m n}=f^{2}+C_{n}^{2}\left(\kappa^{2}+\frac{m^{2} \pi^{2}}{L^{2}}\right) .
\end{aligned}
$$

$c_{m n}$ is the propagation speed of the $m$ th meridional mode and $n$th vertical mode Rossby wave, and $r_{m n}$ is the damping rate due to eddy dissipation. Depending on the vertical and meridional modes, zonal scales of Rossby waves are variable in this model. $\kappa$ is the zonal wavenumber of the Rossby wave with decadal periods (here, we adopted 10 years to examine the decadal change in SSH studied by Nagano et al. (2016)); in other words, we set $\kappa=$ $2 \pi /\left(10\right.$ year $\left.\times c_{m n}\right)$, although the calculated $\mathrm{SSH}$ is little dependent of $\kappa$. Therefore, variations in pressure caused by impacts of the change in wind stress at location $x_{0}$ at time $t_{0}$ propagate with the distinctive speed of $c_{m n}$ as a Rossby wave, being subject to damping at the rate of $r_{m n}$. Since, in this model, the geostrophic equilibrium is assumed to be instantaneously accomplished (in reality, adjusted through the propagations of inertial gravity waves), an induction of wind stress forcing can excite fluctuations in pressure and velocity both to the east and west of the forcing region.

Note that Eq. (8) is the solution for a sustained forcing with the temporal step function; therefore, we differentiate Eq. (8) with respect to $t_{0}$ to obtain the solution for an impulsive forcing, i.e., a Green's function of long Rossby wave. Next, replacing $t_{0}$ and $x_{0}$ with $t^{\prime}$ and $x^{\prime}$, and integrating with respect to them across the intervals of $(-\infty, t]$ and $\left[x, x_{\mathrm{e}}\right]$, respectively, the total pressure at any time $t$ and any location $(x, y)$ due to the $n$th Rossby wave mode $\left(P_{n}\right)$ is expressed as

$$
\begin{gathered}
P_{n}=\frac{\rho_{0} f^{2}}{\beta D} \phi_{n}(0) \int_{-\infty}^{t} \int_{x}^{x_{\mathrm{e}}} \sum_{m=1}^{\infty} \frac{\partial W_{m}}{\partial t^{\prime}} \sin \left(\frac{m \pi}{L} y\right) \\
\cdot\left\{H\left(x-x^{\prime}\right)-\exp \left[-r_{m n}\left(t-t^{\prime}\right)\right]\right. \\
\left.\cdot H\left[x-x^{\prime}+c_{m n}\left(t-t^{\prime}\right)\right]\right\} \mathrm{d} x^{\prime} \mathrm{d} t^{\prime},
\end{gathered}
$$

where $x_{\mathrm{e}}$ is the position of the eastern boundary. Using $P_{n}$, the variation in SSH due to the change in wind stress $(\eta)$ is estimated to be

$$
\eta=\frac{P_{z=0}}{\rho_{0} g}=\frac{1}{\rho_{0} g} \sum_{n=0}^{\infty} P_{n} \phi_{n}(0),
$$

where $\rho_{0}$ is set to $1025 \mathrm{~kg} \mathrm{~m}^{-3}$. Using the hydrostatic relation, the change in the vertical density distribution due to the $n$th baroclinic mode, i.e., $\rho_{n}$, is expressed as $\rho_{n}=-p_{n} / g h_{n}$.

The volume transport due to the $n$th vertical mode through a zonal line between the longitude of the Kuril Islands $\left(x_{\mathrm{w}}\right)$ and the longitude of $\mathrm{K} 2\left(x_{\mathrm{K} 2}\right)$ from the sea surface $(z=0)$ to a depth of $-D$ is calculated as

$$
\begin{aligned}
Q_{n}=\int_{x_{\mathrm{w}}}^{x_{\mathrm{K} 2}} V_{n} \mathrm{~d} x \int_{-D}^{0} \phi_{n}(z) \mathrm{d} z= & \frac{1}{\rho_{0} f}\left[P_{n}\left(x_{\mathrm{K} 2}\right)-P_{n}\left(x_{\mathrm{w}}\right)\right] \\
& \cdot \int_{-D}^{0} \phi_{n}(z) \mathrm{d} z
\end{aligned}
$$

where $V_{n}$ is the total geostrophic velocity due to the $n$th mode and the geostrophic relationship, $\partial_{x} P_{n}=\rho_{0} f V_{n}$, was used to obtain the right hand side. To estimate the volume transport variation caused by the wind stress change in the interior region, we further assume no perturbation at the western edge of the western boundary current, i.e., $P_{n}\left(x_{\mathrm{w}}\right)=0$. Therefore, the volume transport due to the $n$th vertical mode is approximated as

$$
Q_{n}=\frac{P_{n}\left(x_{\mathrm{K} 2}\right)}{\rho_{0} f} \int_{-D}^{0} \phi_{n}(z) \mathrm{d} z .
$$

The total volume transport $(Q)$ is calculated by summing $Q_{n}$ from $n=1$ to $\infty\left(Q=\sum_{n=1}^{\infty} Q_{n}\right)$. Integrating $\phi$ from the sea surface to the bottom $\left(z=-D_{\mathrm{b}}\right)$, the volume transport due to the baroclinic Rossby wave modes vanishes, i.e., $Q=Q_{0}$. Note that the volume transport should not be identical to the East Kamchatka Current transport because we neglect the pressure variation at the western boundary. If we neglect the time-varying, eddy viscosity, and eddy dissipation terms of Eq. (5), the familiar formula of the Sverdrup balance is obtained. Due to the rapid barotropic $(n=0)$ response to the change in wind stress, the variation in the volume transport calculated by this model, i.e., $Q$, should be nearly identical to those based on the Sverdrup balance, as investigated by Isoguchi et al. (1997), Ishi and Hanawa (2005), and Isoguchi and Kawamura (2006).

To examine the characteristic curves of the barotropic Rossby wave in the study region, we calculated geostrophic contours, i.e., $f / H$, where $H$ is water depth (not shown). Except near the Hawaiian-Emperor seamount chain, the Aleutian Arc, and the western and eastern boundaries of the ocean, the geostrophic contours around the latitudes of $\mathrm{K} 2$ and KNOT are largely parallel to the latitudinal lines. It should be noted that the zonal scale of the meridional deviation of the geostrophic contours is much smaller than those of 
barotropic disturbances $(>70000 \mathrm{~km})$. Accordingly, the barotropic disturbances around the latitudes of $\mathrm{K} 2$ and KNOT excited by the wind stress changes in the interior region are considered to propagate zonally, being not significantly affected by the seamount chain.

\section{Results and discussion}

\section{Calculation of the wind-driven SSH variation}

Using the WOCE P01 CTD data collected in 1999 in the region between $160^{\circ} \mathrm{E}$ and $170^{\circ} \mathrm{E}$, we calculated the average potential density, $\sigma_{\theta}=\rho-1000\left(\mathrm{~kg} \mathrm{~m}^{-3}\right)$, down to a depth of $4000 \mathrm{dbar}, D_{\mathrm{b}}=4000 \mathrm{dbar}$ (Fig. 4a). The potential density steeply increases with depth particularly in the top $200 \mathrm{dbar}$, where the halocline exists and compensates for the temperature inversion in the dichothermal layer (Nagano et al. 2016). These near sea surface characteristics are typical of the early summer density profile in the western subarctic North Pacific. The main pycnocline is present from just below the halocline to a depth of approximately $1500 \mathrm{dbar}$. In this paper, we discretized Eq. (3) in terms of $z$ at intervals of $10 \mathrm{dbar}$ and obtained $C_{n}$ and $\phi_{n}$ by solving the eigenvalue problem.

The eigenfunctions of the lowest four baroclinic Rossby wave modes, i.e., $\phi_{n}(n=1,2,3$, and 4$)$, are shown in Fig. $4 \mathrm{~b}$, concurrent with the vertical structure of the barotropic mode $(n=0)$. The obtained $\phi_{n}$ is found to cross zero $n$ times, i.e., it has $n$ nodes. Although the potential density above the depth of the winter mixed layer $(\sim 110 \mathrm{~m})$ varies seasonally, the structure of the $n$th mode with $n$ nodes under the depth of the winter mixed layer is likely to be almost independent of the CTD observation season.

The calculated phase speeds of the barotropic and baroclinic Rossby waves, $c_{m n}$, are listed in Table 1 ; for the calculation of SSH at K2, we set $f_{0}=1.066 \times 10^{-4} \mathrm{~s}^{-1}$ and $\beta=1.562 \times 10^{-11} \mathrm{~m}^{-1} \mathrm{~s}^{-1}$ at the latitude of $47^{\circ} \mathrm{N}$. The phase speeds of the barotropic $(n=0)$ Rossby waves change depending on the meridional modes from $357.85 \mathrm{~cm} \mathrm{~s}^{-1}(m=1)$ to $23.85 \mathrm{~cm} \mathrm{~s}^{-1}(m=4)$, and the waves can propagate across the northern North Pacific

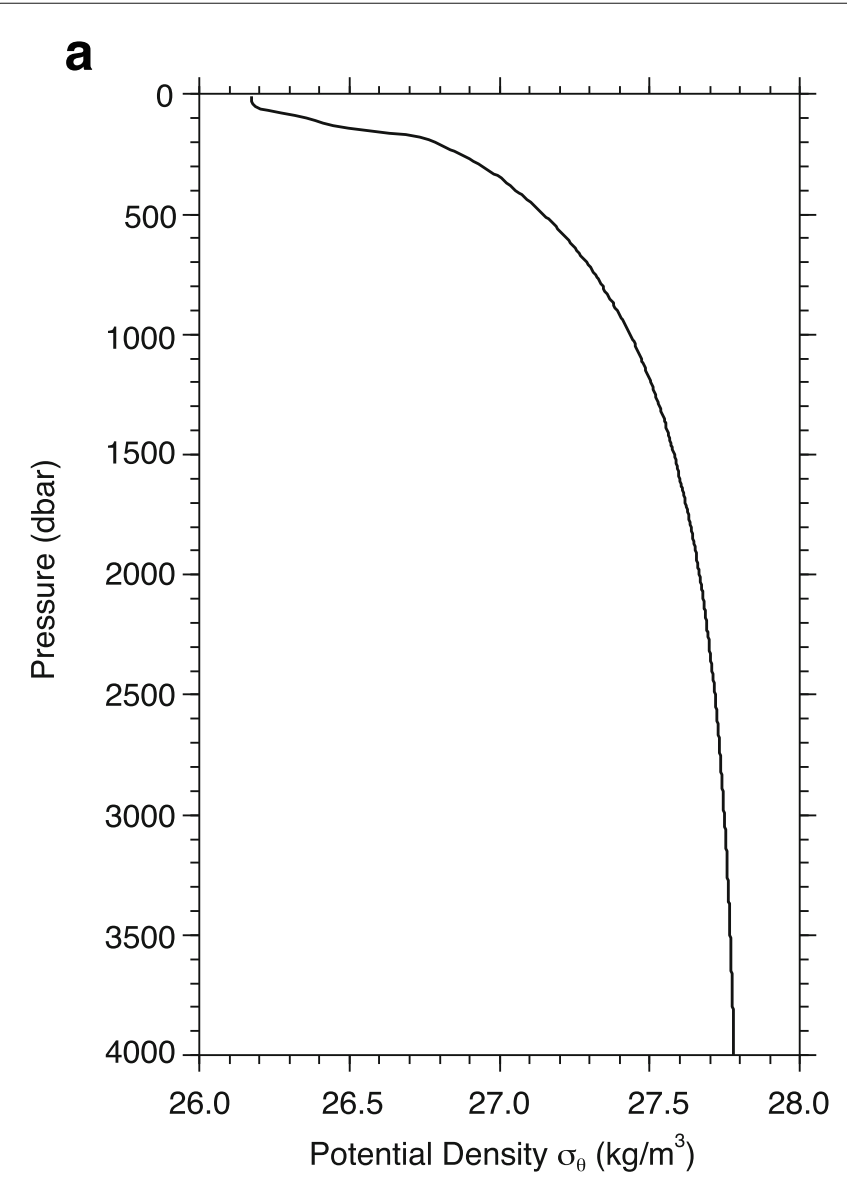

b

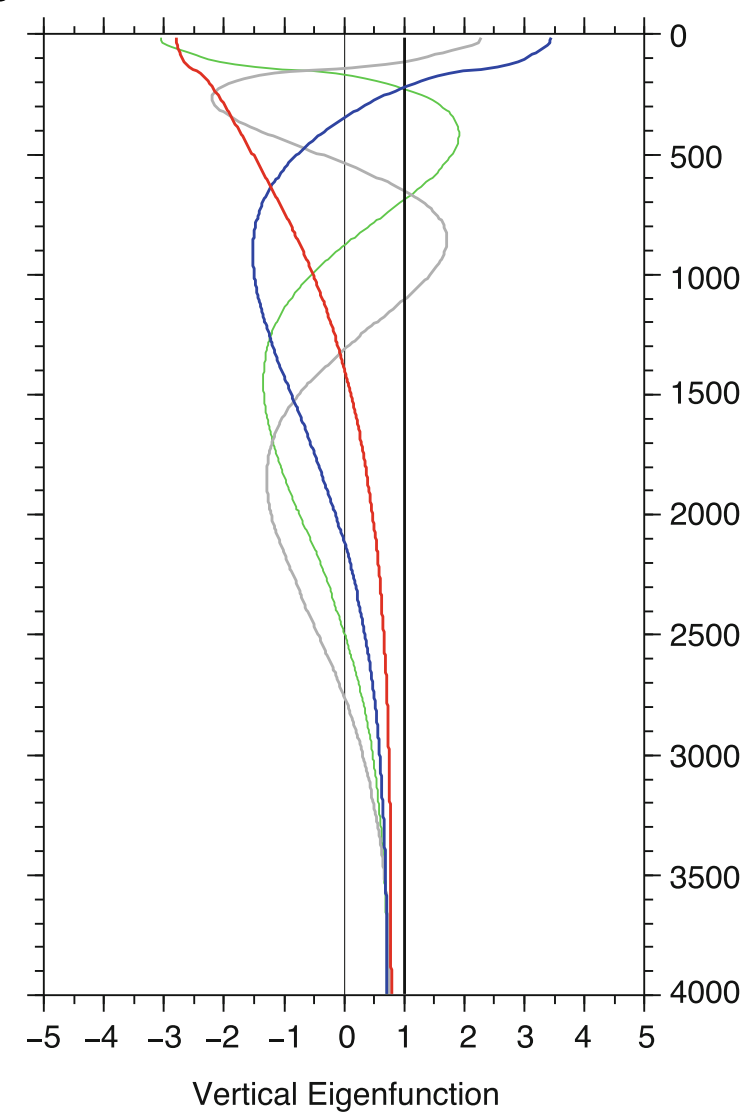

Fig. 4 a Vertical profile of the potential density, $\sigma_{\theta}$, in $\mathrm{kg} \mathrm{m}^{-3}$ averaged along the WOCE P01 line $\left(47^{\circ} \mathrm{N}\right)$ from $160^{\circ} \mathrm{E}$ to $170^{\circ} \mathrm{E}$. b Vertical eigenfunctions of the barotropic mode (black line), and the first (red line), second (blue line), third (green line), and fourth (gray line) baroclinic vertical modes of the potential density profile. The vertical thin solid line indicates zero 
Table 1 Westward propagation speeds $\left(\mathrm{cm} \mathrm{s}^{-1}\right)$ of the Rossby waves, i.e., $c_{m n}$, with respect to the barotropic/baroclinic vertical $(n)$ and meridional $(m)$ modes

\begin{tabular}{|c|c|c|c|c|c|}
\hline \multirow[t]{2}{*}{ Meridional modes } & \multicolumn{5}{|c|}{ Vertical modes } \\
\hline & $n=0$ & $n=1$ & $n=2$ & $n=3$ & $n=4$ \\
\hline$m=1$ & 357.85 & 0.45 & 0.12 & 0.06 & 0.03 \\
\hline$m=2$ & 94.16 & 0.45 & 0.12 & 0.06 & 0.03 \\
\hline$m=3$ & 42.26 & 0.44 & 0.12 & 0.06 & 0.03 \\
\hline$m=4$ & 23.85 & 0.44 & 0.12 & 0.06 & 0.03 \\
\hline
\end{tabular}

basin in shorter than approximately 8 months. Discrepancies of phase speeds at KNOT and K1 due to the $\beta$-plane approximation fixed at $\mathrm{K} 2$ are estimated to be less than $6 \%$, so that the error of travel time of disturbances across the ocean is shorter than the temporal intervals of the $\boldsymbol{\tau}$ data, i.e., 1 month. Baroclinic disturbances are transmitted primarily by the first $(n=1)$ baroclinic Rossby waves with a phase speed of $0.4-0.5 \mathrm{~cm} \mathrm{~s}^{-1}$ but only slightly by the higher baroclinic mode waves because of their slow phase speeds ( $n=2,3$, and 4$)$ and damping due to eddy dissipation. Despite that discrepancies of phase speeds at KNOT and $\mathrm{K} 1$ due to the $\beta$-plane approximation are approximately $17 \%$, spatiotemporal characteristics of calculated SSH variations are not significantly distorted because their propagations are quite slow.

Note that, using the WOD2013 potential density profile around $\mathrm{K} 2$, we obtained the vertical structures of the baroclinic modes and the propagation speeds of Rossby waves. These are basically equivalent to those derived from the WOCE P01 CTD data. However, possibly because the WOD2013 climatology in the western subarctic region was constructed from a small number of data collected in layers deeper than $2000 \mathrm{dbar}$, the WOD2013 data provide artificial discontinuities in $\phi$ around a depth of approximately $2000 \mathrm{dbar}$. Therefore, for the present calculation of wind-driven SSH variations, we adopted the vertical structures and propagation speeds of the baroclinic modes calculated from the WOCE P01 CTD data.

Next, the Ekman vertical velocity, $w_{\mathrm{E}}$, was calculated from the NCEP/NCAR monthly mean momentum flux data. Because $w_{E}$ has a peak around the latitude of $K 2$, we decomposed $w_{\mathrm{E}}$ into the first to fourth meridional modes, as in Eq. (6) ( $m=1,2,3$, and 4$)$, setting $L=14^{\circ}$ latitude (equivalent to $1556 \mathrm{~km}$ ). The mean zonal distributions of the amplitude of the meridional modes, i.e., $W_{m}$, are shown in Fig. 5a. The amplitude of the first meridional mode of $w_{\mathrm{E}}(m=1$, solid black line) is significantly larger than those of the other modes west of approximately $160^{\circ} \mathrm{W}$ owing to the strong westerly wind from the Eurasian continent and gradually decreases eastward. The second meridional mode ( $m=2$, red line) has substantial amplitudes west of approximately $165^{\circ} \mathrm{E}$, and the third ( $m=3$, green line) and fourth $(m=4$, blue line) modes have nearly equivalent amplitudes to the residual error (dashed line) defined as the root-mean-squared difference between the raw and four mode-based synthetic values of $w_{\mathrm{E}}$.

As shown by the standard deviation of $W$ in Fig. 5b, the variations in the amplitudes of the meridional modes are mostly greater with the larger meridional scales expressed by the lower modes. In particular, a significant peak in the standard deviation of the first meridional mode $(m=1$, black line) variation exceeding $0.4 \times 10^{-6} \mathrm{~m} \mathrm{~s}^{-1}$ is present between approximately $150^{\circ} \mathrm{W}$ and $160^{\circ} \mathrm{W}$, where the westerly wind on the southern limb of the Aleutian Low prevails and wind stress curl is correlated to the SSH variation associated with the WSAG change (Fig. 2). The second meridional mode ( $m=2$, red line) has a peak variation near a longitude of approximately $167^{\circ} \mathrm{E}$, the magnitude of which is greater than that of the first meridional mode (black line). This peak variation of the second mode coincides with the variation in wind stress curl in the region southeast of the Kamchatka Peninsula correlated to the WSAG change (Fig. 2). The variations in the third ( $m=3$, green line) and fourth $(m=4$, blue line) meridional modes are significantly smaller than those in the lower modes. Because the meridional scales of higher modes are similar to or smaller than the resolution of the NCEP/NCAR wind stress data $\left(\sim 2.5^{\circ}\right)$, we used the lowest four meridional modes to calculate the variations in $\mathrm{SSH}$ and potential density.

Equation (9) shows that the variation in total pressure can be calculated by the accumulation of linear Rossby wave responses to the changes in wind stress curl from past to time $t$ and from the eastern end to location $x$. It should be noted that because we represented a single fluctuation of $w_{\mathrm{E}}$ by the Heaviside step function of time in Eq. (6), the amplitudes of the variations in pressure and SSH are proportional to the derivative of $W$ with respect to time, i.e., $\partial W / \partial t^{\prime}$ in Eq. (9) (because the derivative of the step function is the $\delta$ function). Therefore, to calculate the amplitude of the Rossby waves excited by the wind stress curl changes, we computed the differences in $W$ between successive months for every longitudinal grid.

To determine the parameters related to damping due to vertical and horizontal eddy diffusion, we calculated variations in SSH, by using Eq. (10) and setting $D_{\mathrm{H}}$ (the horizontal eddy diffusion coefficient) to $0 \mathrm{~m}^{2} \mathrm{~s}^{-1}, 1 \mathrm{~m}^{2} \mathrm{~s}^{-1}$, $10 \mathrm{~m}^{2} \mathrm{~s}^{-1}, 50 \mathrm{~m}^{2} \mathrm{~s}^{-1}$, and $100 \mathrm{~m}^{2} \mathrm{~s}^{-1}$; and $B$ (the vertical eddy diffusion coefficient) to $0 \mathrm{~m}^{2} \mathrm{~s}^{-3}, 1 \times 10^{-8} \mathrm{~m}^{2} \mathrm{~s}^{-3}$, $5 \times 10^{-8} \mathrm{~m}^{2} \mathrm{~s}^{-3}, 1 \times 10^{-7} \mathrm{~m}^{2} \mathrm{~s}^{-3}$, and $2 \times 10^{-7} \mathrm{~m}^{2} \mathrm{~s}^{-3}$. Note that, at $\mathrm{K} 2$, the $\mathrm{SSH}$ variation is considered to be driven purely by the wind stress change to the east without being affected by topographic blocking and other gyre variations, in comparison with those at other sites such as K1 and KNOT. Accordingly, we determined the parameters 


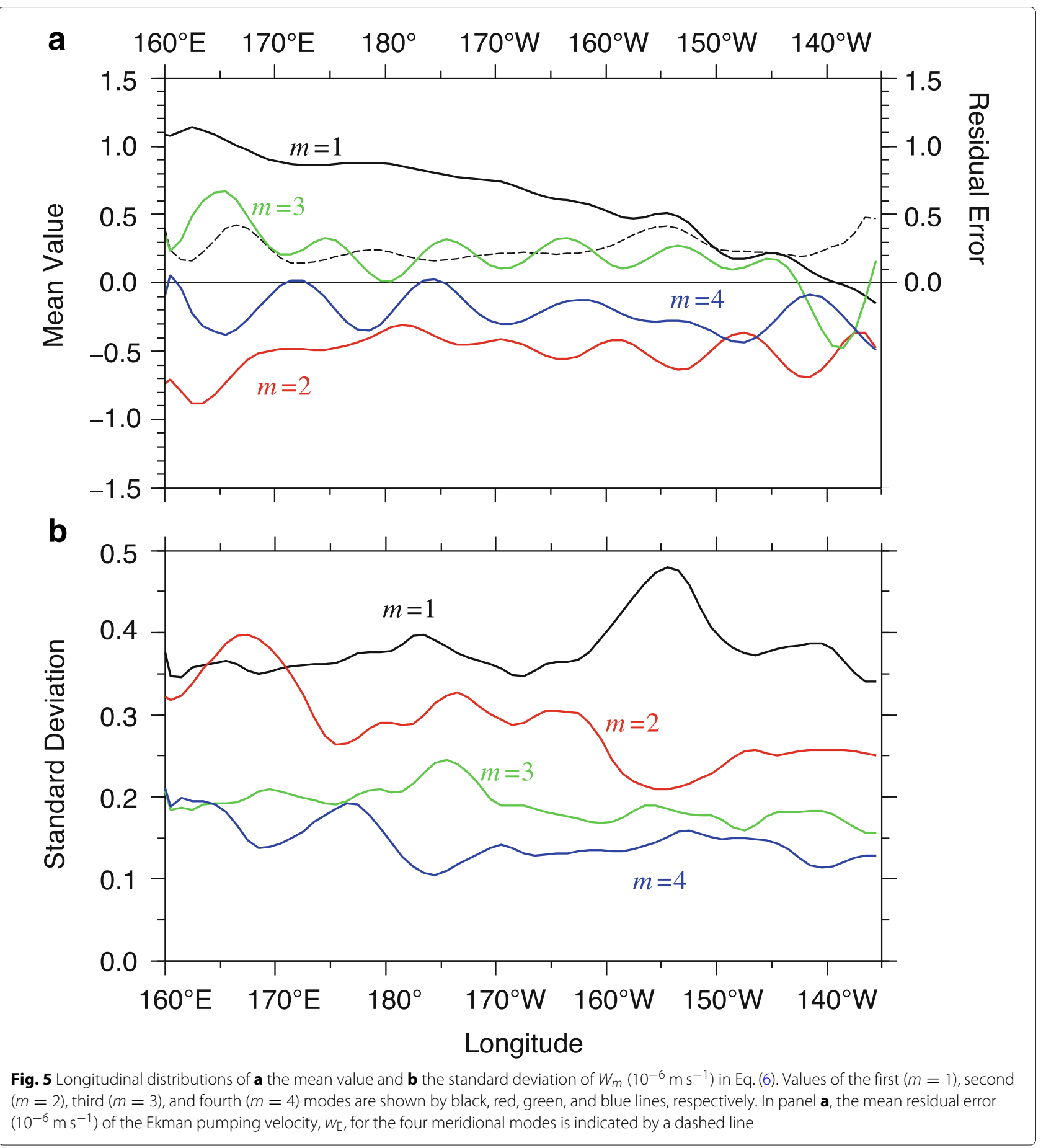

based on the SSH variation at K2. Correlation coefficients between the observed and calculated $\mathrm{SSH}$ are listed in Table 2; to focus on decadal variations, we smoothed calculated SSH time series by using a 35-month running mean filter. The highest correlation is found to be 0.79 for the case of $D_{\mathrm{H}}=10 \mathrm{~m}^{2} \mathrm{~s}^{-1}$ and $B=1 \times 10^{-7} \mathrm{~m}^{2} \mathrm{~s}^{-3}$, which is higher than the $90 \%$ confidence interval $(0.73)$ for 4 equivalent degrees of freedom based on Student's $t$ test. The estimated SSH variations are not sensitive to the diffusion parameters within ranges of $0<D_{\mathrm{H}}<$ $100 \mathrm{~m}^{2} \mathrm{~s}^{-1}$ and $5 \times 10^{-8}<B<2 \times 10^{-7} \mathrm{~m}^{2} \mathrm{~s}^{-3}$ (Table 2). As described below, reasonable decadal increases in $\mathrm{SSH}$ were computed at other sites in the western subarctic region. Therefore, we analyzed the SSH variations 
Table 2 Dependence of the correlation coefficients between the observed and simulated SSH at station $\mathrm{K} 2$ on the eddy dissipation coefficients $B\left(\mathrm{~m}^{2} \mathrm{~s}^{-3}\right)$ and $D_{\mathrm{H}}\left(\mathrm{m}^{2} \mathrm{~s}^{-1}\right)$

\begin{tabular}{llllll}
\hline$D_{H}$ & $B$ & & & & \\
\cline { 2 - 6 } & 0 & $1 \times 10^{-8}$ & $5 \times 10^{-8}$ & $1 \times 10^{-7}$ & $2 \times 10^{-7}$ \\
\hline 0 & 0.436 & 0.358 & 0.758 & 0.785 & 0.781 \\
1 & 0.423 & 0.366 & 0.759 & 0.786 & 0.781 \\
10 & 0.333 & 0.421 & 0.763 & 0.788 & 0.784 \\
50 & 0.267 & 0.498 & 0.744 & 0.767 & 0.763 \\
100 & 0.337 & 0.507 & 0.712 & 0.735 & 0.731 \\
\hline
\end{tabular}

Time series smoothed by a 35-month running mean filter were used for the calculations

based on the values of $D_{\mathrm{H}}\left(=10 \mathrm{~m}^{2} \mathrm{~s}^{-1}\right)$ and $B$ (= $1 \times 10^{-7} \mathrm{~m}^{2} \mathrm{~s}^{-3}$ ) that provide the highest correlation. The value of $D_{\mathrm{H}}$ for the subpolar region is two orders of magnitude smaller than that for the subtropical region evaluated by Kawabe (2000). This is consistent with the fact that spatial eddy mixing scales in the subpolar region are smaller than those in the subtropical region (Stammer 1998). Meanwhile, the values of $B$ for both regions are similar.

The calculated wind-derived $\mathrm{SSH}$ variation at $\mathrm{K} 2$ smoothed by a 35-month running mean filter is shown by the red thick line in Fig. 7a; for comparison, we display the altimetric SSH variation (blue thick line). The standard deviation of the calculated $\mathrm{SSH}$ variation during the period of the altimetric SSH observation is $4.0 \mathrm{~cm}$, which is comparable to but larger than the standard deviation of the observed $\mathrm{SSH}$ variation $(3.8 \mathrm{~cm})$. It should be noted that the year of the background potential density observation at the WOCE P01 line, i.e., 1999, nearly corresponds to the midpoint of the decadal increase in SSH at K2. This suggests that the selection of the background density profile observed in 1999 is reasonable for the SSH calculation during the study period.

The effects of eddy dissipation on the damping rates are strongly dependent on the baroclinic modes but are mostly independent of the meridional modes (Kawabe 2000). Because the amplitude of the SSH disturbances due to the barotropic Rossby waves $(n=0)$ is not significantly affected by the dissipation, the damping rates, defined as $\exp (-r \times 1$ year $)$ in this paper, are nearly unity (Table 3). Due to the eddy dissipation, the amplitude of the first baroclinic Rossby waves $(n=1)$ attenuates to approximately $40 \%$ after 1 year of propagation following excitation. For the higher baroclinic Rossby modes, i.e., the second $(n=2)$, third $(n=3)$, and fourth $(n=$ 4) modes, variations in SSH nearly vanish within 1 year. Because the propagation speeds of these higher baroclinic Rossby wave modes are slow as described above (Table 1), their contributions are localized around the forcing regions.
Table 3 Damping rates of the SSH disturbances per year, i.e., $\exp \left(-r_{m n} \times 1\right.$ year $)$, with respect to the vertical and meridional modes for the case of $B=1 \times 10^{-7} \mathrm{~m}^{2} \mathrm{~s}^{-3}$ and $D_{H}=10 \mathrm{~m}^{2} \mathrm{~s}^{-1}$

\begin{tabular}{llllll}
\hline Meridional modes & \multicolumn{5}{l}{ Vertical modes } \\
\cline { 2 - 6 } & $n=0$ & $n=1$ & $n=2$ & $n=3$ & $n=4$ \\
\hline$m=1$ & 0.999 & 0.377 & 0.028 & 0.000 & 0.000 \\
$m=2$ & 0.995 & 0.376 & 0.028 & 0.000 & 0.000 \\
$m=3$ & 0.988 & 0.373 & 0.028 & 0.000 & 0.000 \\
$m=4$ & 0.980 & 0.370 & 0.028 & 0.000 & 0.000 \\
\hline
\end{tabular}

We performed comparisons between the calculated and altimetric SSH variations at other sites. The variation in SSH at K1 (marked by the northernmost star in Fig. 3) was calculated using the $w_{\mathrm{E}}$ along the zonal line from $135^{\circ} \mathrm{W}$ to $\mathrm{K} 1$ and its correlation coefficient $(0.43)$ is much lower than the $90 \%$ confidence interval. As described below, the SSH variation at $\mathrm{K} 1$ appears to be excited west of the southern end of the Aleutian Arc (longitude $\sim 180^{\circ}$ ). Accordingly, we calculated the $\mathrm{SSH}$ variation at $\mathrm{K} 1$ forced by the $w_{\mathrm{E}}$ in the region west of $180^{\circ}$ alone. As a result, the correlation coefficient rose to 0.58 . Therefore, the SSH variation at $\mathrm{K} 1$ is thought not to be affected by changes in the wind stress originated east of the Aleutian Arc but to be forced primarily by the local change in wind stress to the west. However, note that the standard deviation of the calculated $\mathrm{SSH}(3.0 \mathrm{~cm})$ is much smaller than that of the observed SSH $(5.2 \mathrm{~cm})$. It is likely that the interannual to decadal SSH variation at K1 is significantly affected by changes in forcings other than wind stress.

Because station KNOT is located to the west of $160^{\circ}$ E (Fig. 3), i.e., outside the calculation region, we cannot compute the $\mathrm{SSH}$ variation at this site. Instead, we obtained the SSH variation at a site east of KNOT, i.e., $44^{\circ} \mathrm{N} 160^{\circ} \mathrm{E}$, and compared it to the observed SSH variation at this location. Even though the correlation coefficient between the calculated and observed variations in $\mathrm{SSH}$ is 0.51 , which is lower than the $90 \%$ confidence interval, due to the influences of the subtropical water from the south (Tsurushima et al. 2002), the calculated SSH increases, consistent with the increase in observed SSH that we focus on in this paper. The decadal increase in $\mathrm{SSH}$ east of KNOT may be due to the change in wind stress in the subpolar region, as will be discussed below.

$\mathrm{SSH}$ disturbances can also propagate from the far east, outside the calculation region. Disturbances generated in the equatorial region due to El Niño propagate along the equator and the North American coast as equatorial and coastal Kelvin waves, and proceed westward as baroclinic Rossby waves (e.g., Endfield and Allen 1980 and Jacobs et al. 1994). Perhaps, other types of disturbances on interannual to decadal timescales are also excited by various kinds of forcing. Disturbances excited in the narrow 
region near the North American coast should be carried by baroclinic Rossby waves with a horizontal scale of the internal Rossby radius of deformation. Therefore, such disturbances decay just west of the coast due to the significant damping (Qiu et al. 1997) and do not affect the SSH variation in the western subarctic region.

As described below, this simple wind-driven Rossby wave model should be noted to exhibit some discrepancies between the simulated and observed SSH variations. The discrepancies are supposed to be attributable principally to two reasons. First, topographic effects such as the joint effect of baroclinicity and bottom relief (JEBAR), through which the ocean slowly respond to rapid forcing changes, were not taken into account in the model. As speculated by Frankignoul et al. (1997), the ocean can slowly respond in the barotropic manner to shorter timescale wind stress changes and produce variations on longer timescales. In the present model, the atmospheric variations caused by El Niño excite substantial depressions in SSH, but they were not observed prominently by the satellite altimetry. Accordingly, the El Niño-related SSH depressions are not convincing.

Second, the damping parameters were assumed to be uniform in the whole subpolar region. Characteristics of propagations of SSH fluctuations appear to be different with respect to longitudes. In Fig. 6, we show the spatial distribution of correlation coefficient between altimetric and simulated decadal SSH variations in the subpolar region. Significantly high-correlation $(>0.73)$ areas are present in the northwestern and eastern parts of the calculation region. It should be, however, noted that a low-correlation (reaching minimum values of approximately -0.2 ) area extends southwestward from $50^{\circ} \mathrm{N}$, $160^{\circ} \mathrm{W}$ to $40^{\circ} \mathrm{N}, 165^{\circ} \mathrm{E}$ bounded by the western and eastern high-correlation areas. This distribution of the low correlation is different from those of major bottom topographies such as the Hawaiian-Emperor seamount chain (Fig. 3) but is likely to be a propagating baroclinic Rossby wave pattern. As in the present model, we set the damping parameters to obtain reasonable SSH variation in the WSAG region, disturbances propagating as baroclinic Rossby waves from the eastern to central subpolar North Pacific might be more suppressed than in the real ocean.

Nevertheless, fluctuations in SSH excited in the eastern high-correlation area rapidly propagate westward as barotropic Rossby waves through the low-correlation area in Fig. 6 and contribute to the simulated SSH variations in the high-correlation western subarctic region, so that the wind-driven SSH variation component in the target region, i.e., the western subpolar North Pacific, is considered to be appropriately computed.

\section{Wind-driven SSH and volume transport changes}

Along with the decadal increase in altimetric SSH at K2 (blue thick line in Fig. 7a), the wind-driven SSH at that site (red thick line) increased during the altimetry observation period. The increase in SSH is found to have begun in the late 1990s, being consistent with the result of Nagano et al. (2016). To obtain the linear trend excluding sharp interannual variations, we examined the statistical significance by the Mann-Kendall trend test (e.g., Wilks 2019). Based on the Mann-Kendall trend test, Kendall's $\tau$ coefficient of the calculated wind-driven SSH change during the period of 1993-2014 at the site is 0.43 . This value is higher than the 99\% confidence level (0.11); in other words, this increasing trend is statistically significant. Accordingly, the $\mathrm{SSH}$ change can be approximated by a linear trend. Using Sen's method (Sen 1968), the linear trend was computed to be $0.54 \mathrm{~cm}_{\text {year }}{ }^{-1}$, which is the same order of magnitude as the $0.66 \mathrm{~cm}_{\text {year }}{ }^{-1}$ of the altimetry SSH trend during the same period.

At $\mathrm{K} 1$ and the site east of KNOT, the wind-driven increases in SSH were calculated to be 0.13 and

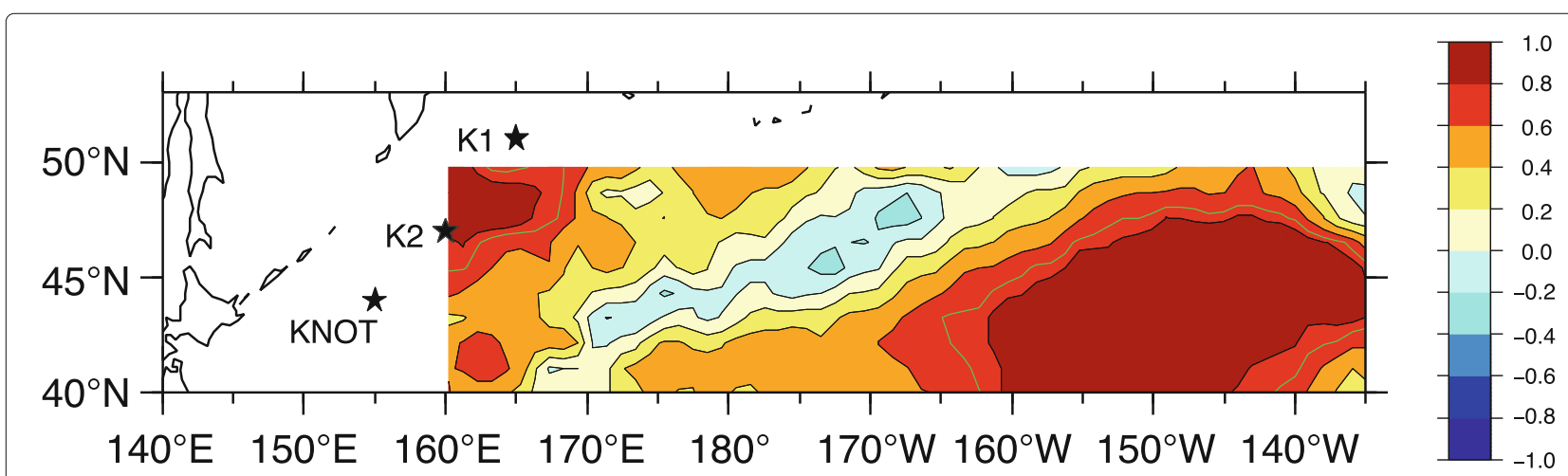

Fig. 6 Map of correlation coefficient between altimetric and simulated SSH variations in the region of $40-50^{\circ} \mathrm{N}, 160^{\circ} \mathrm{E}-135^{\circ} \mathrm{W}$. Contour interval is 0.2. The $90 \%$ confidence interval (0.73) is illustrated by green contours. Variations in SSH smoothed by a 35 -month running mean filter were used to calculate correlation coefficients. Locations of stations K1, K2, and KNOT are indicated by stars 


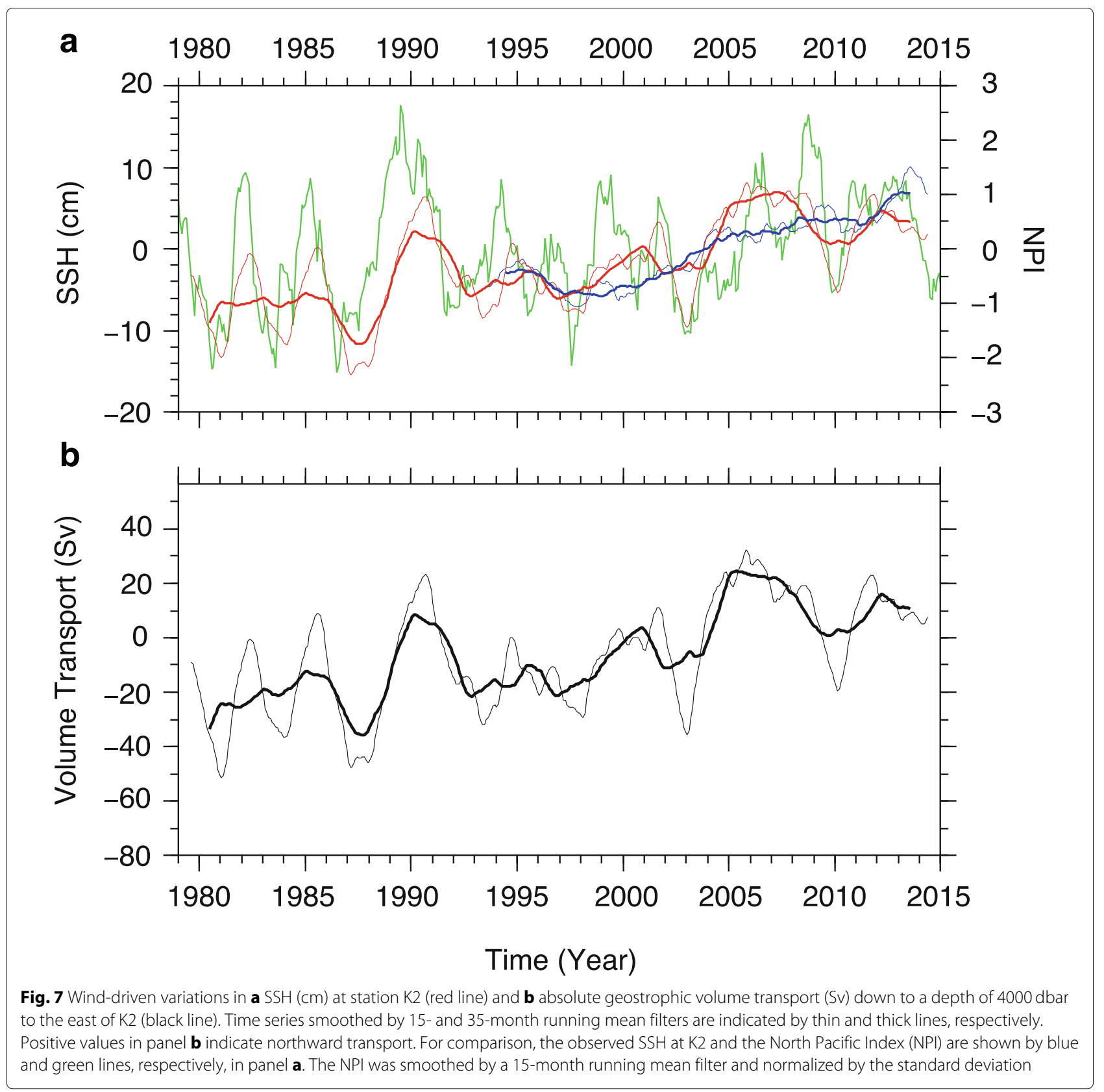

$0.49 \mathrm{~cm}$ year $^{-1}$, respectively (red lines in Fig. 8a and c). According to the above Kendall's criterion, these trends are also statistically significant. In particular, the winddriven SSH elevation at the site east of KNOT is larger than the observed trend $\left(0.38 \mathrm{~cm} \mathrm{year}^{-1}\right)$ (Fig. 8c). The magnitudes of the wind-driven SSH increases at $\mathrm{K} 2$ and the site east of KNOT are sufficiently large to explain the observed northward shrinkage of the WSAG. Therefore, it is suggested that the decadal SSH change is mostly attributable to the change in wind stress. Meanwhile, at $\mathrm{K} 1$, the calculated trend is much smaller than the observed value $\left(0.67 \mathrm{~cm}\right.$ year $\left.^{-1}\right)$ (Fig. $\left.8 \mathrm{a}\right)$, the northern part of the circulation being strongly affected by other factors than wind stress. On the basis of the decadal wind-driven SSH changes, the onset of the SSH increase occurred in order from the south, as in 1992, 1997, and 2004 at KNOT, K2, and K1, respectively (arrows in Fig. 8).

The intensification of the Aleutian Low via the atmospheric teleconnection by El Niño is illustrated by the depressions in the area-weighted sea level atmospheric pressure in the region of $30-65^{\circ} \mathrm{N}, 160^{\circ} \mathrm{E}-140^{\circ} \mathrm{W}$, called the North Pacific Index (NPI) (Trenberth and Hurrel 1994). In association with the intensification of the Aleutian Low in winter, interannual ( $\sim 3$-year) timescale 
a

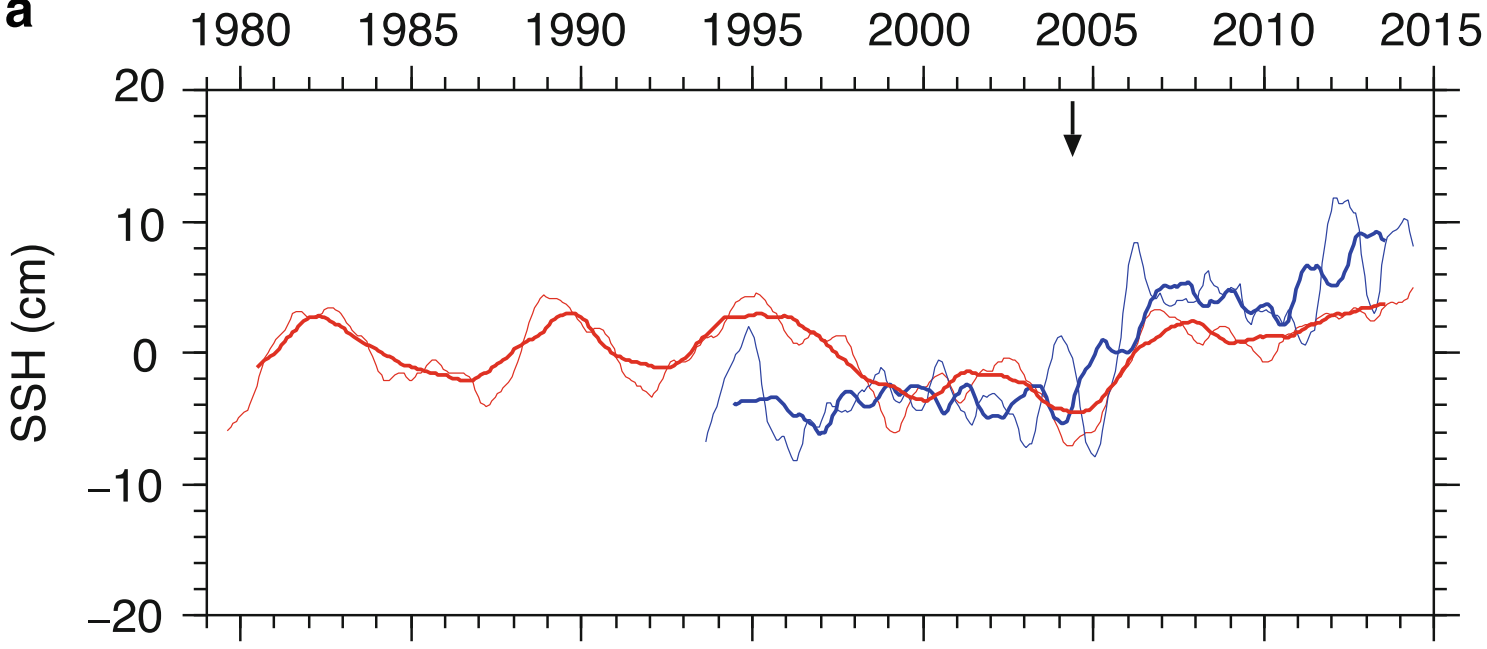

b
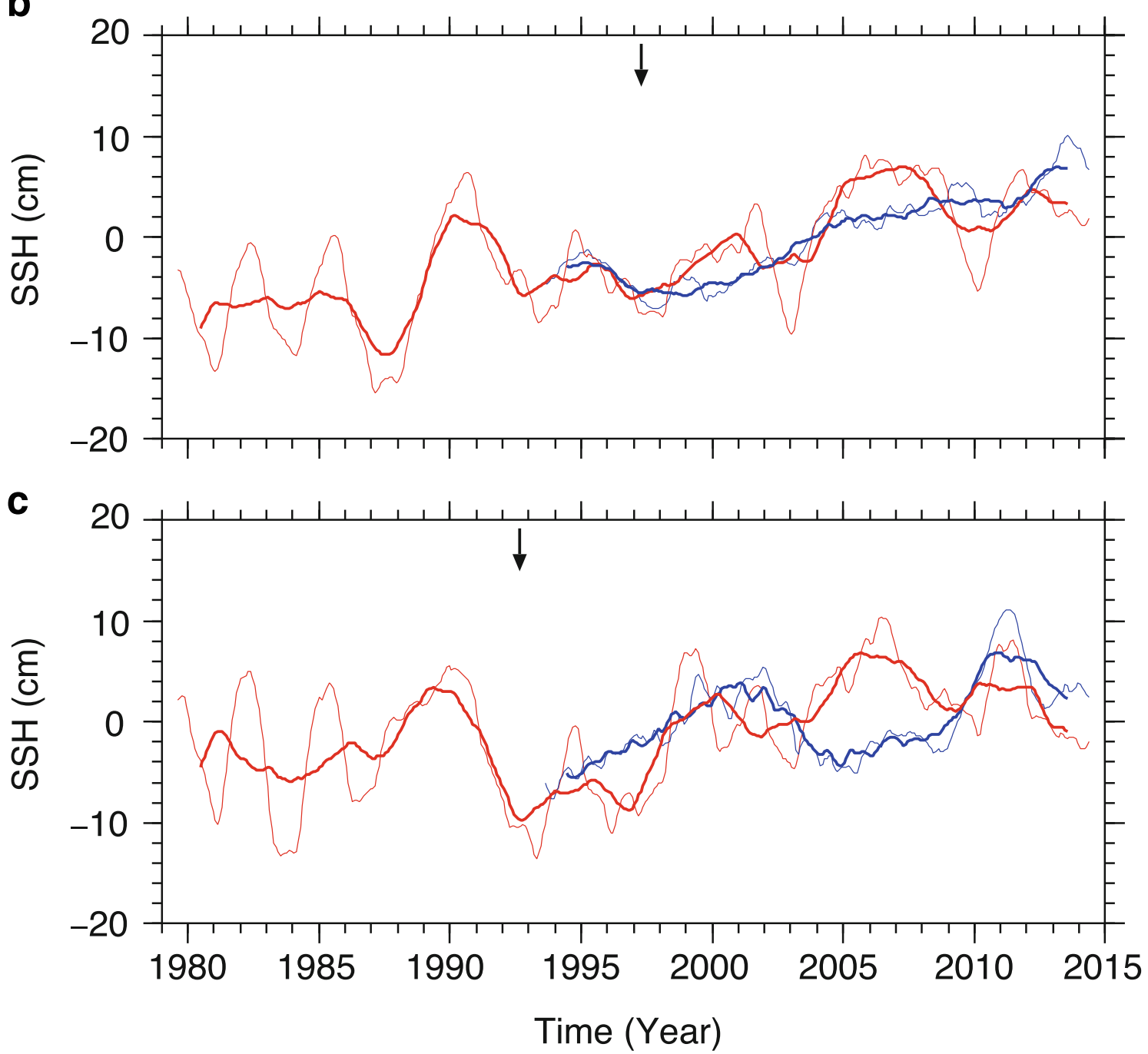

Fig. 8 Wind-driven (red lines) and altimetry-based (blue lines) variations in SSH at stations a K1, b K2, and c east of KNOT. Smoothed time series by 15- and 35-month running mean filters are denoted by thin and thick lines, respectively. Arrows show estimated times at the latitudes when SSH began to increase due to the WSAG shrinkage 
depressions were produced in calculated SSH at K2 (red thin lines in Figs. 7a and $8 \mathrm{~b}$ ) and the site east of KNOT (red thin line in Fig. 8c). However, no clear corresponding depressions were observed in altimetric SSH at $\mathrm{K} 2$ and KNOT. In Fig. 9, we display Hovmöller diagrams of the altimetric $\mathrm{SSH}$ variations at the latitudes of $\mathrm{K} 1, \mathrm{~K} 2$, and KNOT. In altimetric SSH, negative SSH disturbances were generated in 1995, 1998, 2003, and 2010 at K2 and KNOT (arrows in Fig. 9b and c) when the Aleutian Low was intensified by El Niño and induced positive fluctuations in wind stress, $w_{\mathrm{E}}$, in regions to the east of approximately $180^{\circ}$ (arrows in Fig. 10b and c). Similar negative SSH disturbances are found also at $\mathrm{K} 1$ in the El Niño years (arrows in Fig. 9a) except in 1995 and the corresponding $w_{\mathrm{E}}$ fluctuations occurred to the east of approximately $160^{\circ} \mathrm{W}$ (arrows in Fig. 10a). By the satellite altimetry, the El Niño-related negative SSH disturbances at the latitudes of KNOT and K2 reached the sites in 2003 and 2010, respectively, but other negative SSH disturbances appear to be canceled out around or to the east of the sites by regional positive disturbances to the west of $\sim 170^{\circ} \mathrm{W}$ (K1 and $\mathrm{K} 2$ ) or $\sim 180^{\circ}$ (KNOT).

Meanwhile, the disturbances in SSH excited by the El Niño-related enhancement of the Ekman suction, i.e., the increases in $w_{\mathrm{E}}$, at the latitudes of K2 (Fig. 11b) and KNOT (Fig. 11c) are calculated to reach the western end of the calculation region (arrows) and they are shown by the significant SSH depressions in Fig. 8b and c. At the latitude of K1 (Fig. 11a), the El Niño-related SSH dips were generated to the east of $180^{\circ}$ and sometimes to the west. Also, in the opposite phase of El Niño-Southern Oscillation (ENSO), i.e., La Niña, elevations in $\mathrm{SSH}$ are excited at the latitudes of $\mathrm{K} 2$ and KNOT by the relaxations of the Ekman suction. The spatiotemporal patterns of the total wind-driven SSH variations at the latitudes (Fig. 11) are fairly similar to and dominated by those of the barotropic $\mathrm{SSH}$ variations (Fig. 12). Remarkably, the ENSO-timescale variations are nearly simultaneously exited by the barotropic $(n=0)$ Rossby wave response to the changes in wind stress to the east of approximately $180^{\circ}$ longitude, which is a region of significant wind variation due to the change in the Aleutian Low (black line in Fig. 5b). The amplitudes of the wind-driven SSH variations diminish toward the farther east.

Probably because topographic effects such as the JEBAR were neglected, the modeled ocean produced significant SSH depressions, which were not comparably observed by the altimetry, in response to short-term El Niño-related intensification of the Aleutian Low. Meanwhile, in the case of La Niña, discrepancies between the simulated and observed SSH changes are not remarkable. The wind variations in the subpolar region through the atmospheric teleconnections from the tropical region consist of fluctuations on timescales shorter than approximately 10 days (e.g., Feldstein 2000). In addition, El Niño decays more rapidly than La Niña (e.g., Ohba and Ueda 2009 and $\mathrm{Hu}$ et al. 2017). Therefore, it should be noted that the ENSOtimescale variation in wind stress forcing is not caused by

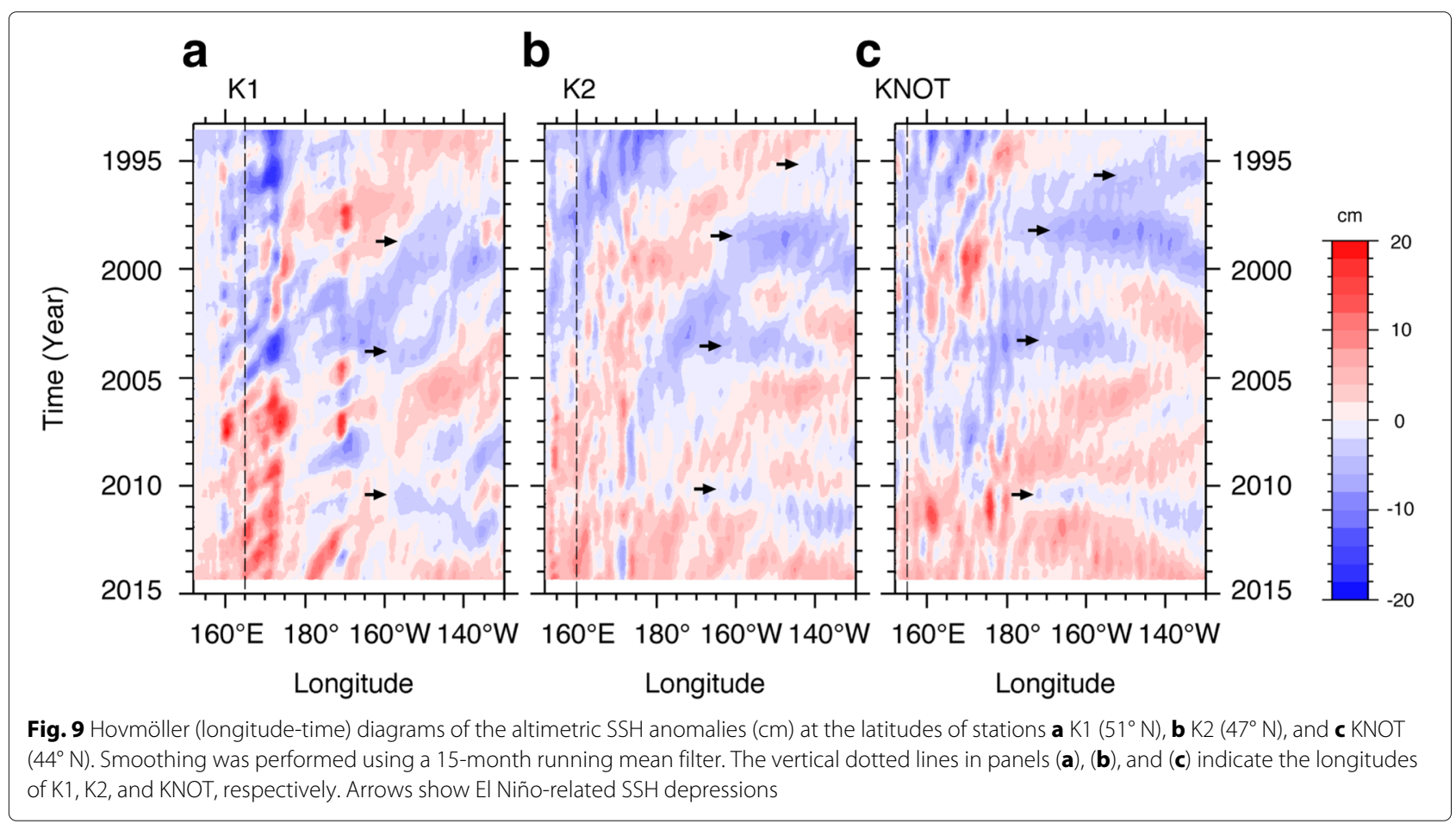




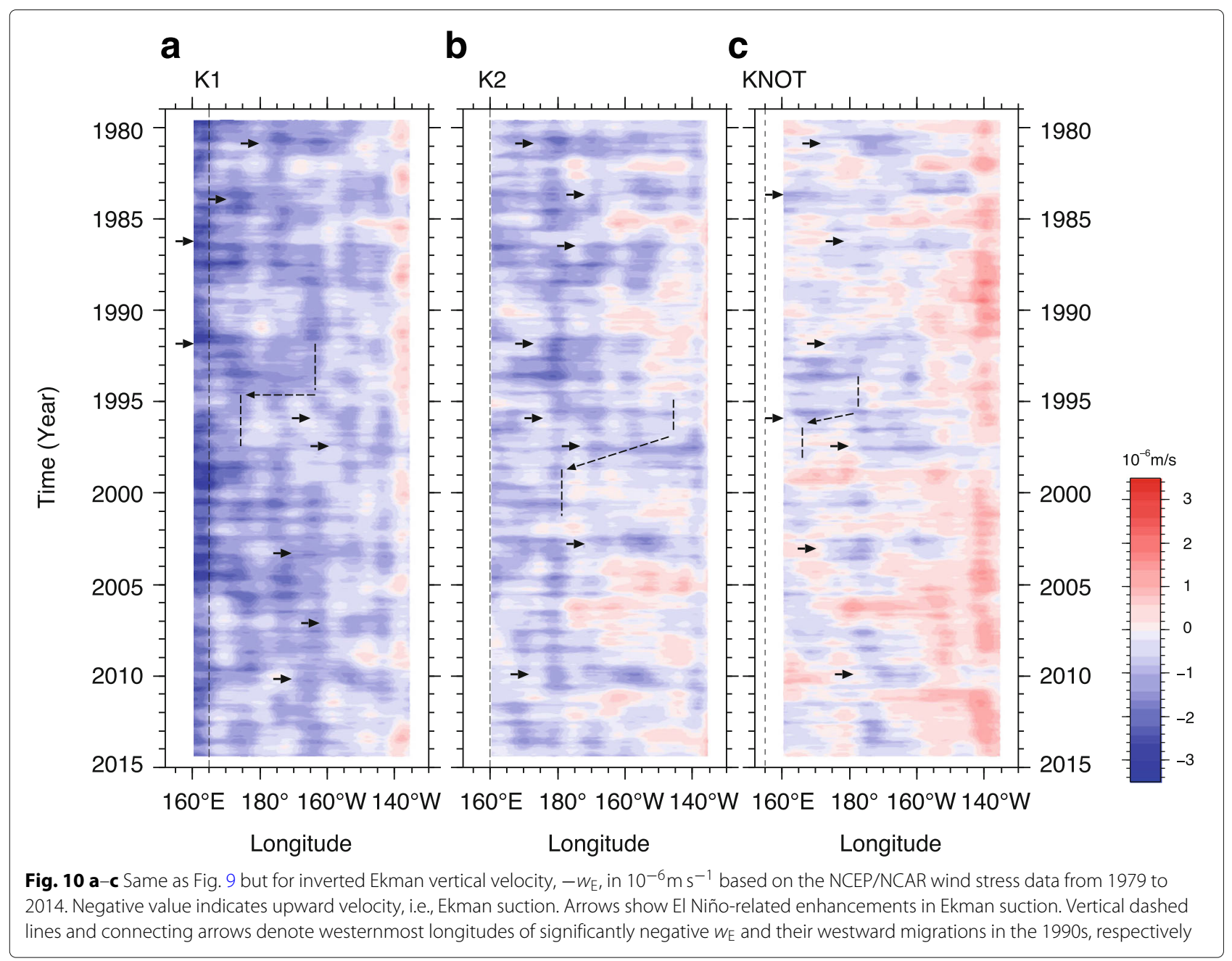

individual pulses of the atmospheric anomalies but their accumulative modulation; more (less) frequent tropical convective activity triggers extratropical wind anomalies in the central to eastern North Pacific more (less) often during El Niño (La Niña) years. These differences might be the reason why the ocean response to El Niño is different from that to La Niña.

From the mid-1990s to the late 1990s, substantially negative $w_{\mathrm{E}}$ exceeding $0.5 \times 10^{-6} \mathrm{~m} \mathrm{~s}^{-1}$ was mostly induced to the east of approximately $140^{\circ} \mathrm{W}$ and $180^{\circ}$ at the latitudes of K2 and KNOT, respectively; note that, in Fig. 10, the signs of $w_{\mathrm{E}}$ were reversed to match the coloring of SSH as in Figs. 9 and 11. In the late 1990s, the negative $w_{\mathrm{E}}$ abruptly migrated to $\sim 180^{\circ}$ longitude at the latitude of K2 (Fig. 10b) and to $\sim 170^{\circ} \mathrm{E}$ at the latitude of KNOT (Fig. 10c), as illustrated by vertical dashed lines and connecting arrows in the figure. After the late 1990s, greatly negative $w_{\mathrm{E}}$ frequently occurred from these longitudes to approximately $140^{\circ} \mathrm{W}$. The frequent relaxation of the Ekman suction is attributed to the attenuation of the Aleutian Low due to the increase in occurrences of substantial La Niña from the late 1990s to mid-2000.

Associated with this westward jump of the forcing relaxation in the late 1990s, positive SSH anomalies seem to have propagated westward from approximately $150^{\circ} \mathrm{W}$ at the latitudes of $\mathrm{K} 2$ and KNOT. Additionally, at the latitude of K1, a westward jump of the wind forcing relaxation was observed in the mid-1990s (Fig. 10a). Although the amplitude of the forcing change at the latitude of $\mathrm{K} 1$ is smaller than those at the latitudes of $\mathrm{K} 2$ and KNOT, the corresponding $\mathrm{SSH}$ elevation at $\mathrm{K} 1$ was as great as those at the other latitudes. The propagation speed from $150^{\circ} \mathrm{W}$ to $180^{\circ}$ is estimated to be approximately $1.3 \mathrm{~cm} \mathrm{~s}^{-1}$, which is much slower and faster than the estimated propagation speeds of the barotropic and baroclinic Rossby waves, respectively, as reported by Chelton and Schlax (1996) (Table 1). The background flow in this region is up to eastward $\sim 15 \mathrm{~cm} \mathrm{~s}^{-1}$ (e.g., Roden 2000), which is opposite to the propagation of Rossby waves. The northward shoaling of the main pycnocline is quite little (e.g., Roden 2000). 


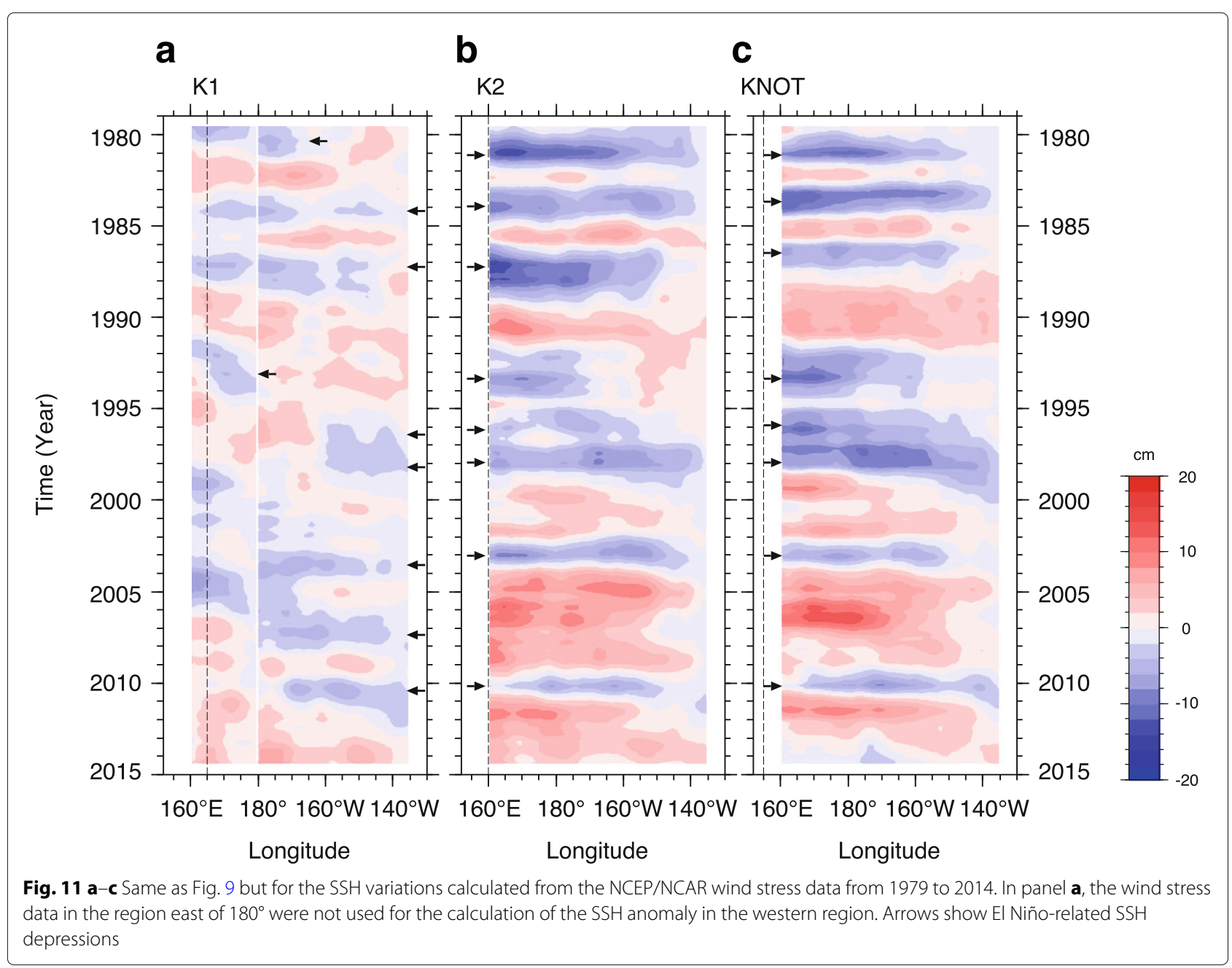

Despite taking into account of the background state, the propagation of this disturbance observed by the altimetry cannot be interpreted as the free baroclinic Rossby waves alone. Presumably, this propagating signal is a result of superposition of SSH fluctuations due to barotropic and baroclinic Rossby waves forced by the westward jump of the Ekman suction relaxation, although, in the model, the disturbance is rapidly damped just east of $\sim 160^{\circ} \mathrm{W}$ due to the strong dissipation and is rather depressed by the 1997/1998 El Niño.

The frequent relaxation of the Ekman suction after the late 1990s caused the long-term elevation in SSH at the latitudes of K2 (Figs. 11b and 12b) and KNOT (Figs. 11c and 12c). In particular, the attenuations of the Aleutian Low due to the 2005/2006 and 2007/2008 La Niña greatly contribute to the decadal SSH elevation, i.e., substantial northward shrinkage of the WSAG, in the mid to late 2000s. In addition, there is a long-term decrease in $w_{\mathrm{E}}$ at the latitudes of $\mathrm{K} 2$ and KNOT to the west of $\sim 180^{\circ}$ longitude due to the weakening of the westerly wind
(Fig. 9b, c), which contributes to the increase in $\mathrm{SSH}$ at $\mathrm{K} 2$ and KNOT.

Using Eq. (12), we estimated the geostrophic volume transport relative to a depth of $1000 \mathrm{dbar}$ in the western boundary region of the WSAG between the Kuril Islands and K2, as Nagano et al. (2016) calculated. The standard deviation of the volume transport is approximately $0.1 \mathrm{~Sv}$ (where $1 \mathrm{~Sv}=10^{6} \mathrm{~m}^{3} \mathrm{~s}^{-1}$ ). On the basis of AGEMbased hydrographic data, Nagano et al. (2016) calculated the geostrophic volume transport in the top $1000 \mathrm{dbar}$ layer at a westward line from the point of the maximal amplitude of the $\mathrm{SSH}$ variation $\left(53^{\circ} 38^{\prime} \mathrm{N}, 164^{\circ} 30^{\prime} \mathrm{E}\right)$. Associated with the northward shrinkage of the WSAG, the AGEM-based volume transport of the gyre changed from approximately southward $1.0 \mathrm{~Sv}$ in 1996 to northward $0.5 \mathrm{~Sv}$ in 2003 (see thick dashed line Fig. 9 in Nagano et al. 2016). The variabilities in the AGEM-based and wind-driven volume transports are comparable to each other but are one or two orders of magnitude smaller than the Sverdrup transport of $5 \mathrm{~Sv}$ (July) to $40 \mathrm{~Sv}$ (February) 


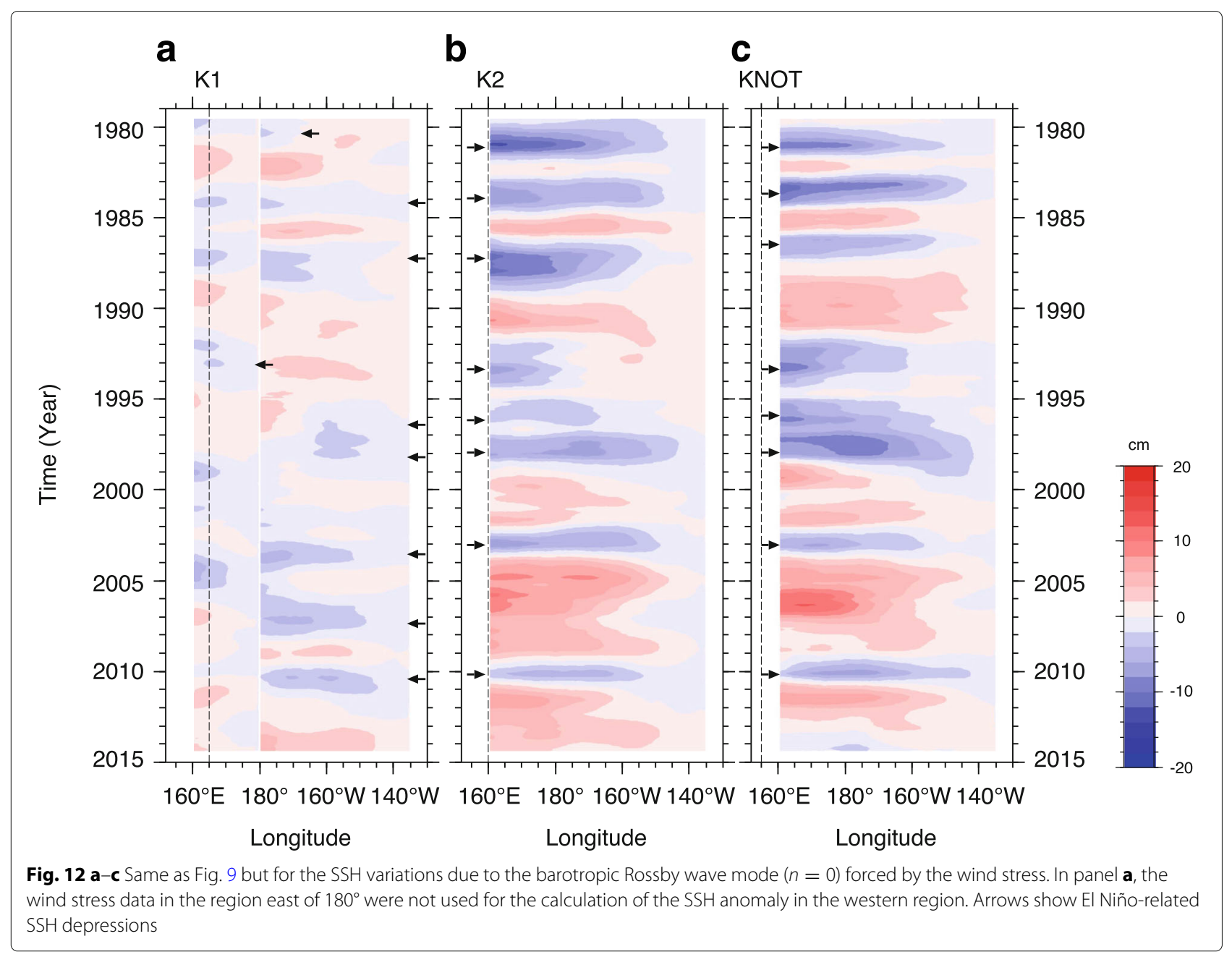

by Favorite et al. (1976) and the climatological wintertime Sverdrup transport of $\sim 40 \mathrm{~Sv}$ by Ishi and Hanawa (2005). The wind-driven volume transport in the layer from the sea surface to $4000 \mathrm{dbar}$, i.e., full-depth wind-driven volume transport, varied with a large standard deviation of 15.4 Sv. The small variability in the AGEM-based transport is attributed to the small vertical displacement of the main pycnocline. Therefore, the baroclinic variability might be really the minor component in the decadal wind-driven $\mathrm{SSH}$ and volume transport variations in the western subarctic region, as suggested by the present SSH computation.

The full-depth volume transport of the extended WSAG (Fig. 7b) was approximately southward $20 \mathrm{~Sv}$ in 1994, when Nagano et al. (2016) examined the streamfunction from the sea surface to a depth of $1000 \mathrm{dbar}$, and it was larger in the period prior to the early 1990s. The volume transport in the extended gyre state is consistent with the estimated values of the Sverdrup transport $(5-40 \mathrm{~Sv})$ in past studies. After the early 2000s, the East Kamchatka Current returned northeastward to the north of $\mathrm{K} 2$ due to the northward shrinkage of the WSAG; therefore, the volume transport vanished in the early 2000s and was occasionally positive, i.e., northward. This is consistent with the distribution of the streamfunction of the diminished WSAG in 2004 prepared by Nagano et al. (2016).

At the latitude of $\mathrm{K} 1$, near the west coast of North America $\left(\sim 140^{\circ} \mathrm{W}\right)$, a substantial Ekman pumping (downward velocity) is present through the study period but is quite limited, yielding a significant SSH elevation to the west. Even though the barotropic disturbances are generated by the wind stress changes in the central region between approximately $140^{\circ} \mathrm{W}$ and $180^{\circ}$ (Fig. 12a), they are likely to be shielded by the Aleutian Arc, as described above. The disturbances locally generated in the area between $\mathrm{K} 1$ and longitude $180^{\circ}$ affect SSH at K1.

Figure 13 shows pentad mean wind-driven SSH maps during 1995-1999, 2000-2004, and 2005-2009. During 1995-1999, just after the onset of the gyre shrinkage (Fig. 13a), the cyclonic WSAG is produced in the western subarctic region, as illustrated by a low SSH to the west of approximately $175^{\circ} \mathrm{W}$. The WSAG is considerably 


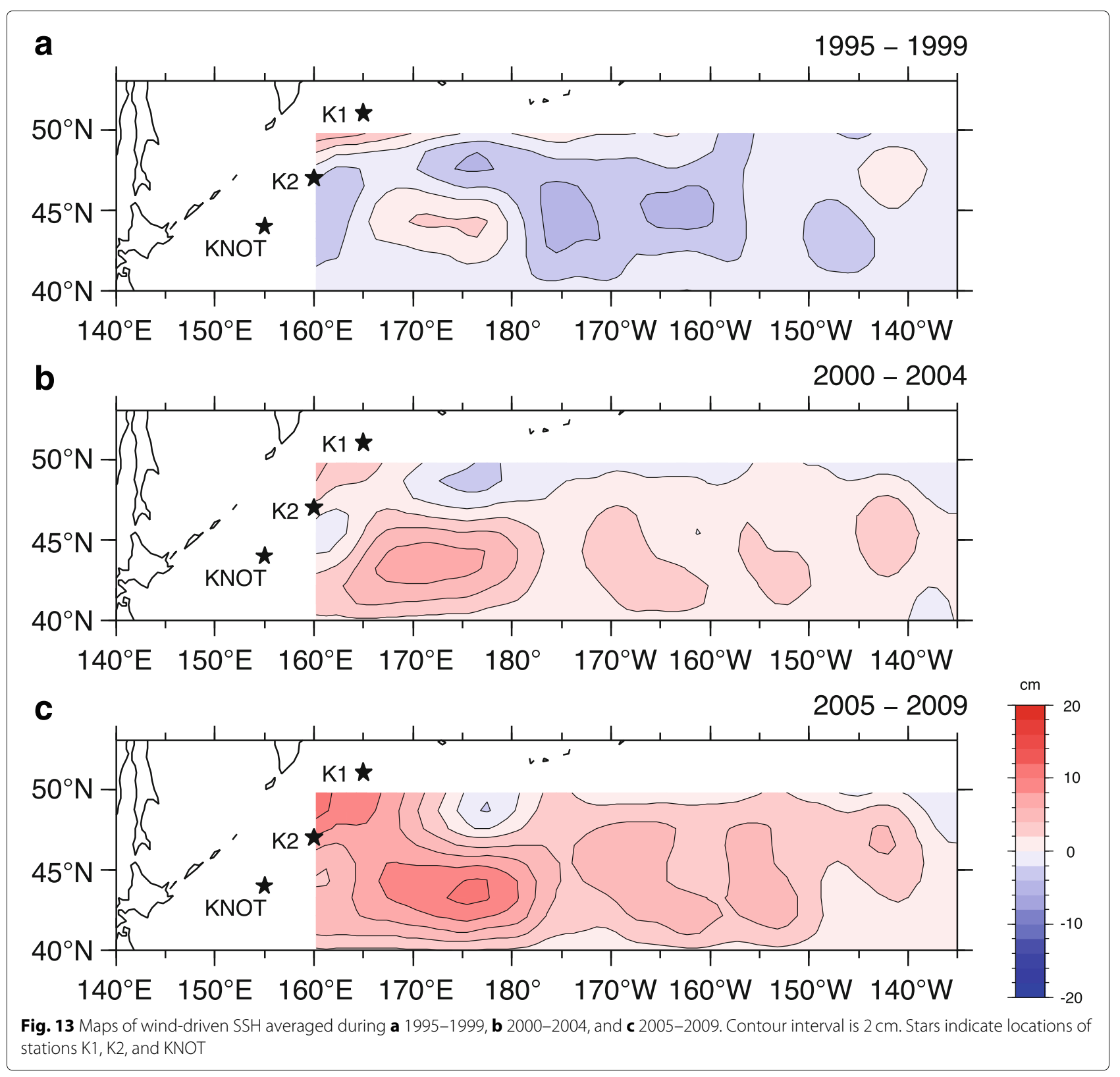

reduced in its extension and is present only around the east of station K2 during 2000-2004 (Fig. 13b), and eventually disappears around K2 during 2005-2009 (Fig. 13c). The gyre shrinkage is associated with a substantial anticyclonic circulation centered around $43-44^{\circ} \mathrm{N}, 170-175^{\circ} \mathrm{E}$, southeast of the WSAG (Fig. 13b, c), which has been developed from a weak SSH peak around $44^{\circ} \mathrm{N}, 175^{\circ} \mathrm{E}$ during 1995-1999 (Fig. 13a). Owing to the meridional scales of the WSAG and the anticyclonic circulation $(\sim 500 \mathrm{~km})$, the SSH change in the western subarctic region is fairly affected by the second meridional mode $(m=2)$. Despite prominent variations with smaller spatial scales $(100-200 \mathrm{~km})$ in altimetric $\mathrm{SSH}$, the simulated wind-driven change of the WSAG is basically consistent with the gyre shrinkage observed by the satellite altimetry (Fig. 14).

However, unlike calculated wind-driven SSH, altimetric SSH did not change significantly or decreased from 19901995 (Fig. 14a) to 2000-2004 (Fig. 14b) in the central area where the correlation between these SSH fields is low (Fig. 6). Intriguingly, the anticyclonic circulation is accompanied by a northeastward current at the western edge of the circulation (Fig. 13). The corresponding northeastward current anomalies are found in the altimetric $\mathrm{SSH}$ 


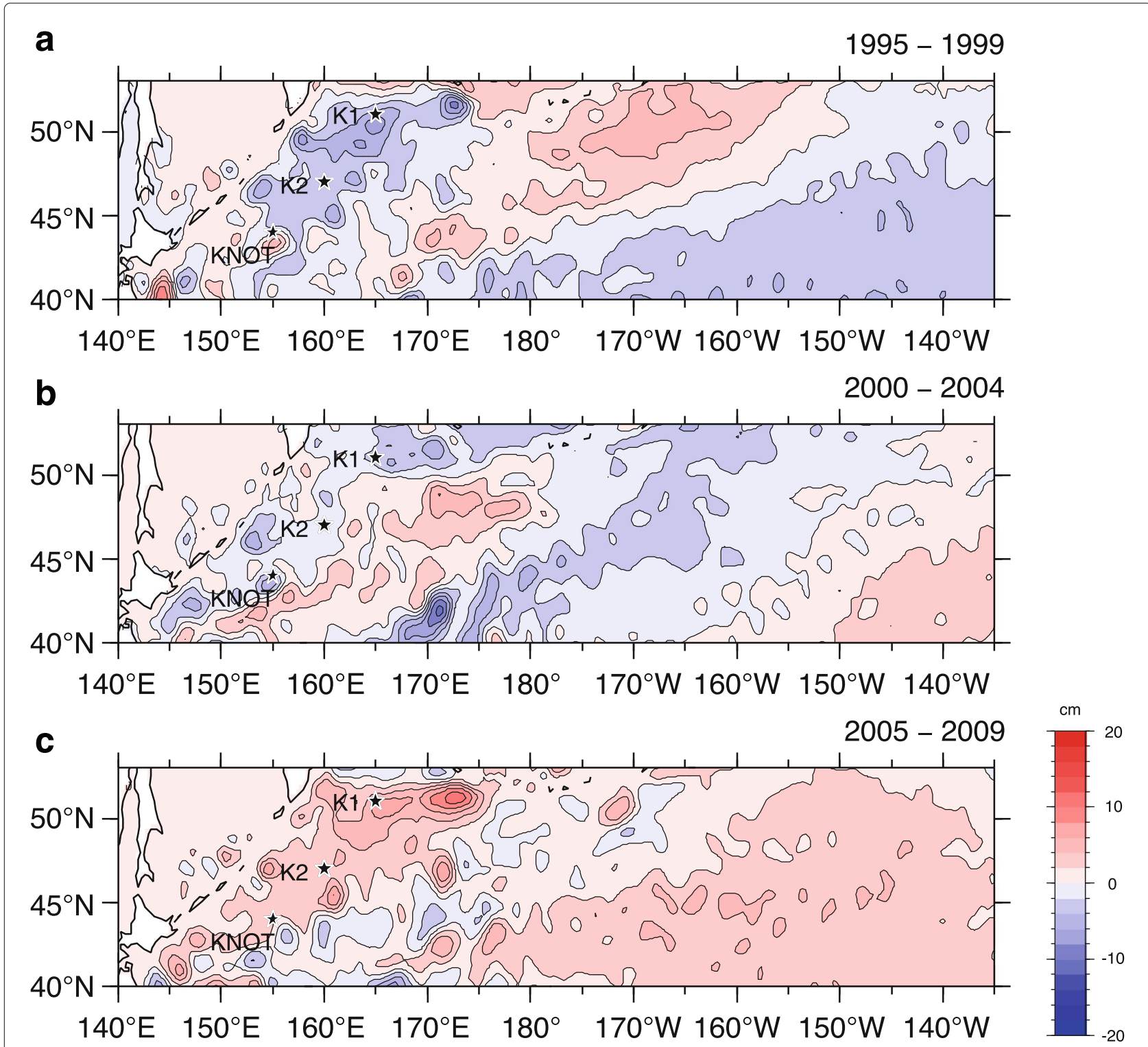

Fig. 14 a-c Same as Fig. 13, but for altimetric SSH anomaly from the mean state

anomaly maps (Fig. 14) and are coincident with a northeastward jet from around $43^{\circ} \mathrm{N}, 160^{\circ} \mathrm{E}$ to $45^{\circ} \mathrm{N}, 170^{\circ} \mathrm{E}$ (J2) reported by Isoguchi et al. (2006).

Qiu (2002) reported that the SSH variation in the initial phase of the WSAG shrinkage is caused by the baroclinic Rossby wave adjustment to the change in wind stress. Meanwhile, the present calculation of the winddriven SSH variation demonstrates that the barotropic Rossby wave adjustment is primarily responsible for the northward shrinkage of the gyre. We think that the difference is attributable to that of the dissipation rates used in the models. The dissipation rate used in Qiu (2002) is much smaller (6-year damping) than that in the present model (approximately 1-year damping for the first baroclinic mode) (Table 3). Note that the SSH variation which Qiu (2002) used to determine the dissipation rate is dominated by the variation on the annual timescale (Fig. 19b in Qiu 2002). On the other hand, as described above, we determined the eddy dissipation coefficients by fitting the $\mathrm{SSH}$ variations on interannual to decadal timescales. This is likely to be the reason why the dissipation rate used in Qiu (2002) is much smaller. If we set $B$ to a lower value, $1 \times 10^{-8} \mathrm{~m}^{2} \mathrm{~s}^{-3}$, without changing other parameters, we obtain a smaller rate of the increase in SSH at $\mathrm{K} 2$ $\left(0.35 \mathrm{~cm}\right.$ year $\left.^{-1}\right)$. Thus, the wind-driven decadal increase in $\mathrm{SSH}$ in the western subarctic region is considered to 
be more exactly estimated in the present model with the higher dissipation, which substantially attenuates the baroclinic disturbances in the western region.

Remember that the eigenfunction of the barotropic mode is vertically constant (the black line in Fig. 4 b), so that the vertical gradient, i.e., $\mathrm{d} \phi_{0} / \mathrm{d} z$, is zero. The barotropic Rossby wave response to the change in wind stress is not associated with the density change. Conversely, disturbances due to the baroclinic Rossby waves are expected to be associated with the density changes because $\mathrm{d} \phi_{n} / \mathrm{d} z \neq 0(n=1,2,3$, and 4$)$. In particular, the vertical gradients of the modes higher than the first are remarkable just beneath a depth of approximately $110 \mathrm{dbar}$, where the winter mixed layer does not reach (Wakita et al. 2017) and the variations in the sea surface heat and freshwater fluxes are considered to be ineffective. The baroclinic Rossby wave responses and the associated potential density changes will be discussed in the next subsection.

\section{Wind-driven potential density change}

The amplitudes of the SSH variations due to the baroclinic Rossby wave responses to the changes in wind stress at the latitudes of K1, K2, and KNOT (Fig. 15) are smaller than those of the SSH variations due to the barotropic response (Fig. 12) but are larger than the error of the satellite altimetric observations $(\sim 3 \mathrm{~cm})$ (Le Provost 2001$)$. The wind-driven baroclinic SSH variations are primarily generated not by remote wind stress changes via westward propagations of Rossby waves but by local changes in the wind stress. As demonstrated at the latitude of $\mathrm{K} 2$, the baroclinic Rossby wave response to the wind stress change due to the weakening of the westerly wind to the west of $\sim 180^{\circ}$ longitude (Fig. 10b) contributes to the decadal increase in SSH in the western subarctic region during the calculation period (Fig. 15b). This is consistent with the high correlation near K2 between wind stress curl and the SSH change in association with the WSAG shrinkage (Fig. 2).

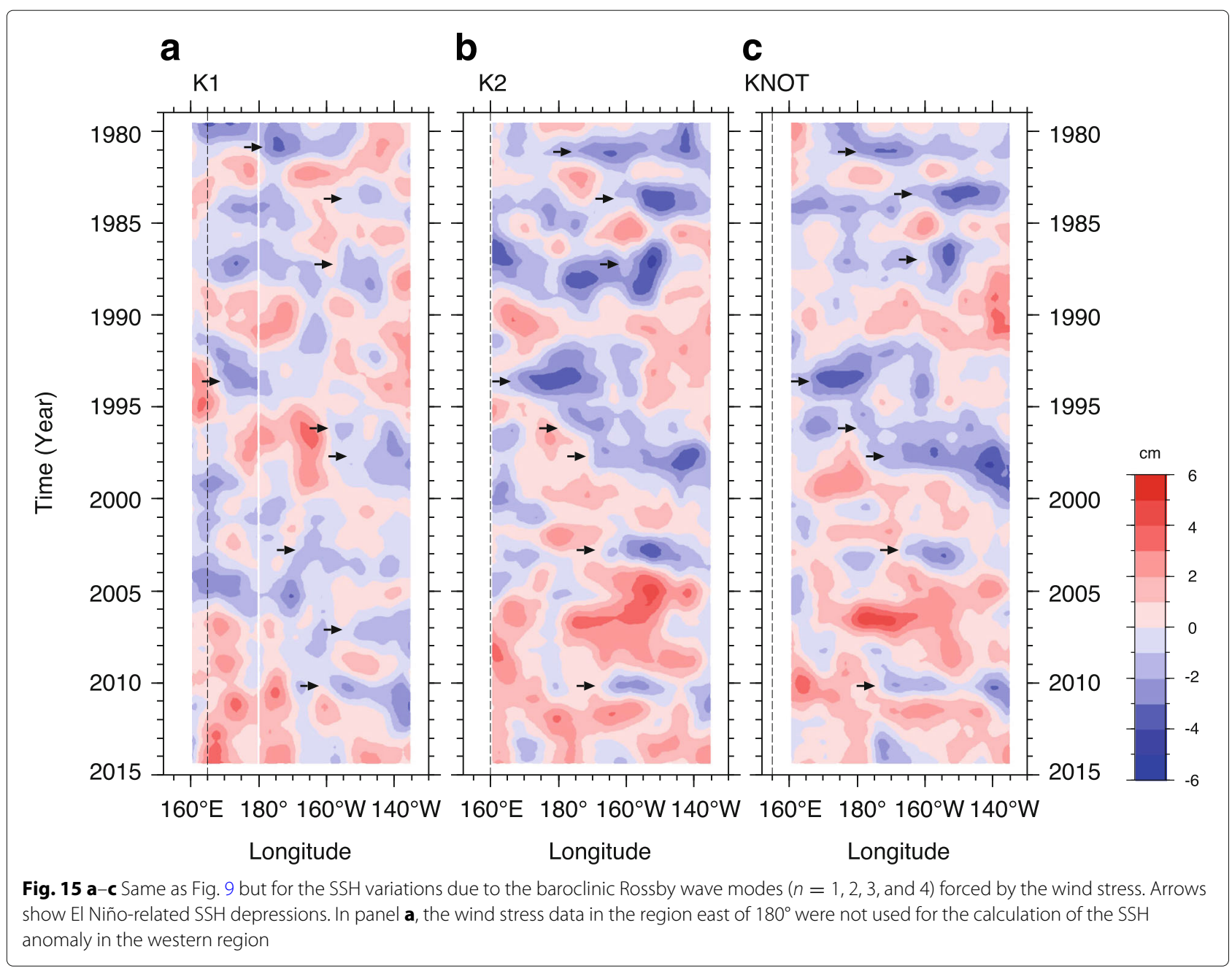




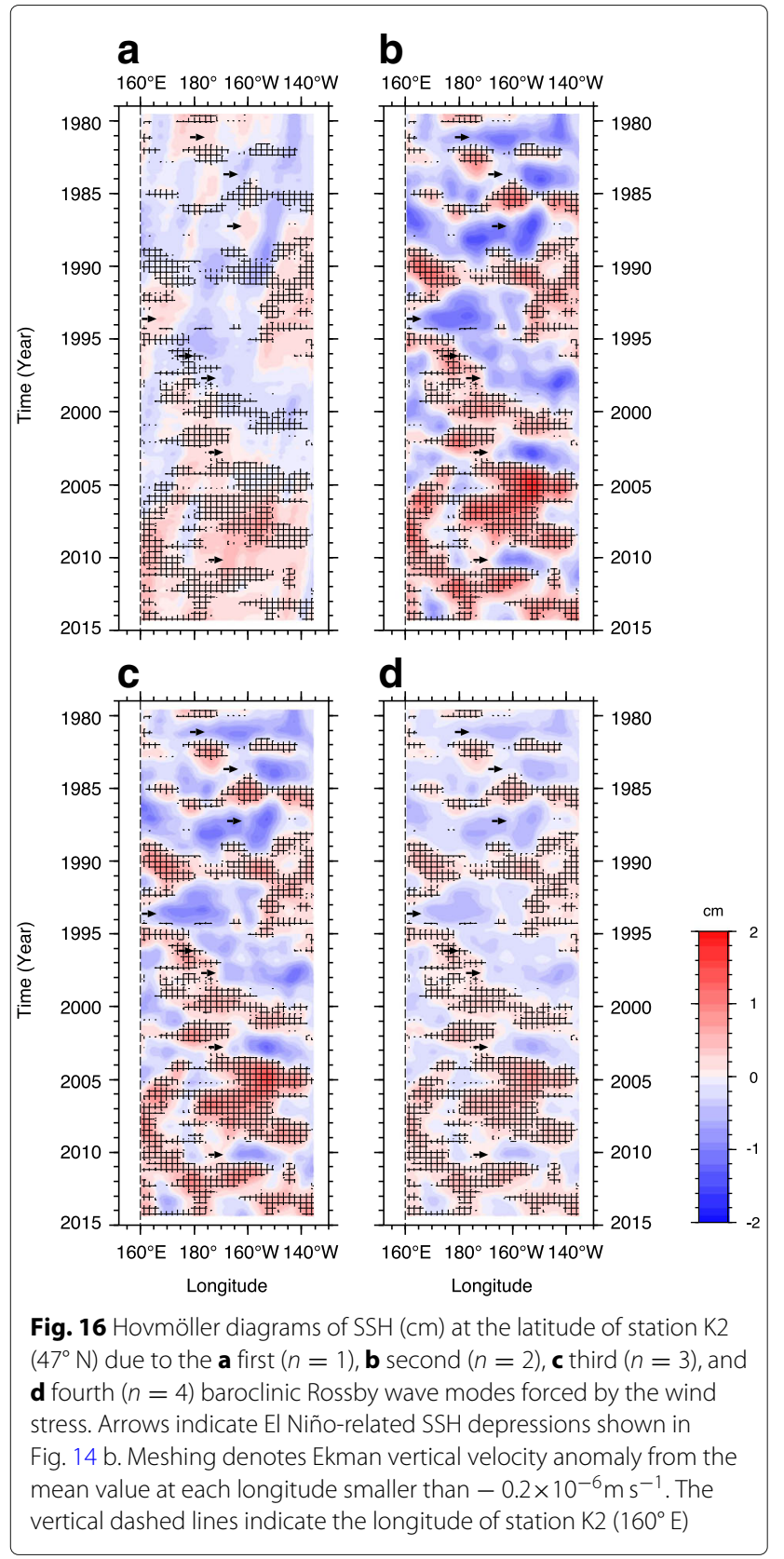

In Fig. 16, we show the first $(n=1)$ to fourth $(n=4)$ baroclinic Rossby wave mode variations in SSH at K2. Spatiotemporal patterns of the variations due to the second $(n=2)$ to fourth $(n=4)$ modes (Fig. 16b, c, and d), which amplitudes are proportional to $\phi(0)^{2}$ because of no significant propagations, are similar to each other but rather different from that of the propagating first $(n=1)$ mode variation (Fig. 16a). Notably, the SSH elevations due to the second and third baroclinic Rossby wave modes are more prominent than those due to other baroclinic modes and well coincide with anomalously negative forcing in space and time (meshes in Fig. 16b and c). Meanwhile, the SSH elevations by the first baroclinic Rossby wave mode are rapidly dissipated apart from negative forcing times and regions (meshes in Fig. 16a), resulting in smaller amplitudes of disturbances than those by other higher baroclinic modes. There are reports on SSH variabilities due to higher baroclinic mode Rossby waves than the first. For instance, an analysis of the SSH variability in the South Pacific by Maharaj et al. (2007) indicates that the higher baroclinic mode waves contribute to the variations even to the south of $40^{\circ} \mathrm{S}$. Remarkably, in Maharaj et al. (2007), we recognize areas where the amplitudes of the second baroclinic mode variations are greater than those of the first baroclinic mode variations. Their report supports our indication that, also in the western subarctic region, the disturbances due to the higher baroclinic mode waves can have greater $\mathrm{SSH}$ amplitudes than those due to the first baroclinic mode waves.

With respect to the amplification of the higher baroclinic mode variations, it is worthwhile to point out the coincidence between the $w_{\mathrm{E}}$ variation and the $\mathrm{SSH}$ variations due to the second, third, and fourth baroclinic modes. Such persistent wind stress forcing is considered to amplify disturbances until the balance between the forcing and damping is reached. The large amplitudes of the slowly propagating (or quasi-stationary) disturbances of the baroclinic higher modes can be interpreted by a quasi-resonant amplification (QRA). This amplification mechanism has been proposed to explain the reinforcement of quasi-stationary atmospheric Rossby wave disturbances with relatively high horizontal wavenumbers of 6-8 that possibly bring about frequent extreme meteorological events in recent years (e.g., Petoukhov et al. 2013; Coumou et al. 2014; Kornhuber et al. 2017). In case of mid- and high-latitude oceans, fluctuations having large vertical scales rapidly propagate as the first baroclinic Rossby waves after excited by wind stress changes and are subject to the substantial damping. In contrast to the fast traveling fluctuations, the QRA mechanism can be exerted on quasi-stationary fluctuations of the higher baroclinic modes because they continue to be excited as long as forced and are reinforced despite the presence of the damping.

Corresponding to the intensification of the Aleutian Low associated with El Niño (indicated by depressions in the NPI in Fig. 7a), negative SSH anomalies are found in the region between $170^{\circ} \mathrm{E}$ and $170^{\circ} \mathrm{W}$ at the latitudes of K2 and KNOT in 1981, 1983, 1987, 1993, 1997, 2003, and 2010 (arrows in Fig. 15b and c). The SSH disturbances due to the first baroclinic mode $(n=1)$ propagate westward (Fig. 16a) at the estimated propagation speed $\left(0.45 \mathrm{~cm} \mathrm{~s}^{-1}\right.$, Table 2$)$, even though the amplitude of the variation is significantly smaller $(<1 \mathrm{~cm})$ than those of the 
other modes. Most of these ENSO-timescale baroclinic disturbances decayed significantly and did not proceed to $\mathrm{K} 2$ and KNOT. At the latitude of K1, the baroclinic SSH depressions due to El Niño are weak (Fig. 15a) because this site is located to the north of the area of significant variation in Ekman vertical velocity driven by the change in the Aleutian Low.

The baroclinic Rossby wave mode variations, particularly higher baroclinic mode variations than the first, are responsible for the water density change in the subsurface layer around $\mathrm{K} 2$. The vertical distribution in potential density at $\mathrm{K} 2$ is shown by the contours in Fig. 17; to suppress noisy fluctuations on timescales shorter than approximately 3 years, the time series at each pressure level was temporally smoothed using a 49-month running mean filter. Associated with the decadal elevation in SSH at K2 during the study period (Fig. 15b), the upper main pycnocline, which exists within depths of 100 to $300 \mathrm{dbar}$, tended to be deepened (Fig. 17). An anomalously large elevation and depression of the upper main pycnocline were observed in the periods around 1985 and 2006, corresponding to the inductions of negative and positive $w_{\mathrm{E}}$, which are quite limited to the west of $\sim 170^{\circ} \mathrm{E}$ (Fig. 10b), respectively. They greatly contributed to the decadal deepening of the upper main pycnocline. The locality of the main pycnocline depth responded to the wind forcing support that the QRA mechanism plays a crucial role also in the deepening of the main pycnocline depth by the higher baroclinic modes.

We decomposed the variation in potential density into those of the baroclinic Rossby wave modes to examine the contribution of each baroclinic Rossby wave mode to the deepening of the upper main pycnocline (Fig. 18).
In comparison to the first baroclinic Rossby wave mode $(n=1)$, the higher baroclinic modes $(n=2,3$, and 4$)$, which have sharp vertical gradients in the modal structures of the potential density in the top $250 \mathrm{dbar}$ (Fig. 4b), are revealed to contribute greatly to the potential density change.

To perform a comparison with the annual mean time series of the halocline depth indicated by the in situ salinity value of 33.8 processed using ship-board CTD and Argo data by the method of Wakita et al. (2017) (the dashed line in Fig. 19), we computed the annual mean time series of the wind-driven deepening of the upper main pycnocline, defined by the isopycnal surface of $26.8 \sigma_{\theta}$, (the solid line). The wind-driven deepening of the upper main pycnocline is consistent with that of the halocline. The linear trend of the $26.8 \sigma_{\theta}$ isopycnal surface during the period of $1999-2014$ is estimated to be $1.36 \mathrm{~m} \mathrm{year}^{-1}$, which is equivalent to approximately $70 \%$ of the linear trend of the halocline $\left(1.79 \mathrm{~m} \mathrm{year}^{-1}\right)$ estimated from in situ data by Wakita et al. (2017). Therefore, it is concluded that the higher baroclinic mode Rossby wave disturbances excited by the local change in wind stress and reinforced through the QRA mechanism mainly deepened the upper main pycnocline (halocline) depth at $\mathrm{K} 2$.

As described in "Introduction" section, sea surface water density change, which can cause steric sea level change, is not significantly detected in the western subarctic region (Wakita et al. 2017). On the other hand, the precipitation rate (rainfall) gradually increased in the western subarctic region during the study period (not shown). We estimated the impact of the freshwater flux change on the upper-ocean circulation. Using the NCEP/NCAR evaporation rate $(E)$ and precipitation rate

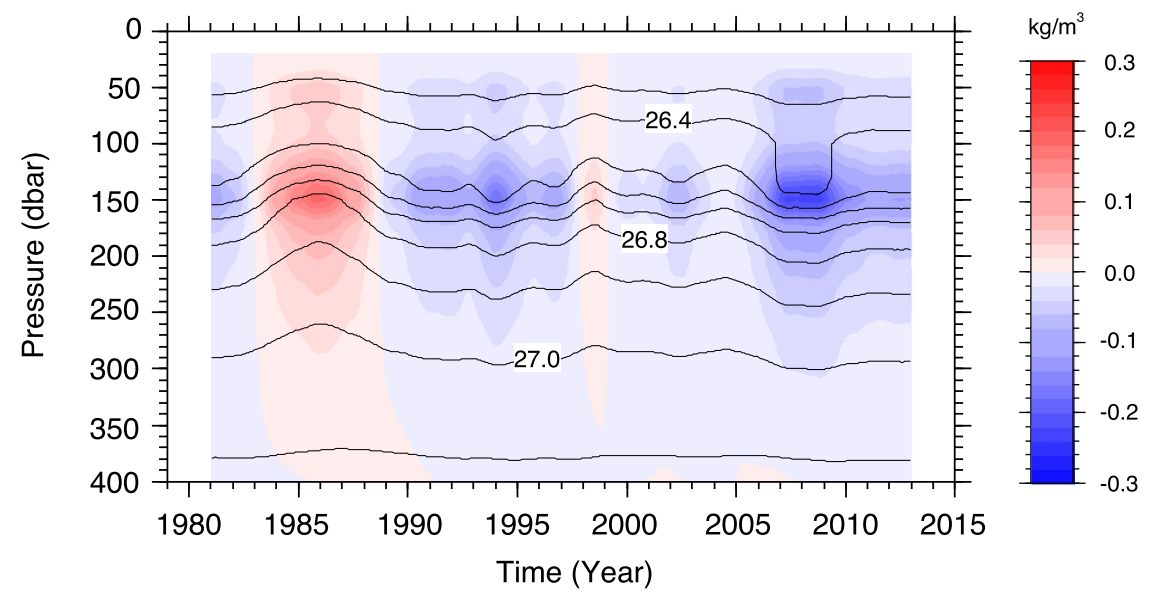

Fig. 17 Time-pressure diagram of the calculated variation in the potential density $\left(\sigma_{\theta}\right.$, contours) due to the baroclinic Rossby wave modes $(n=1,2$, 3 , and 4 ) in the top 400 dbar forced by the wind stress and the calculated anomaly from the mean potential density profile (kg $\mathrm{m}^{-3}$, color shades). The contour interval is $0.1 \mathrm{~kg} \mathrm{~m}^{-3}$. Smoothing was performed using a 49-month running mean filter 


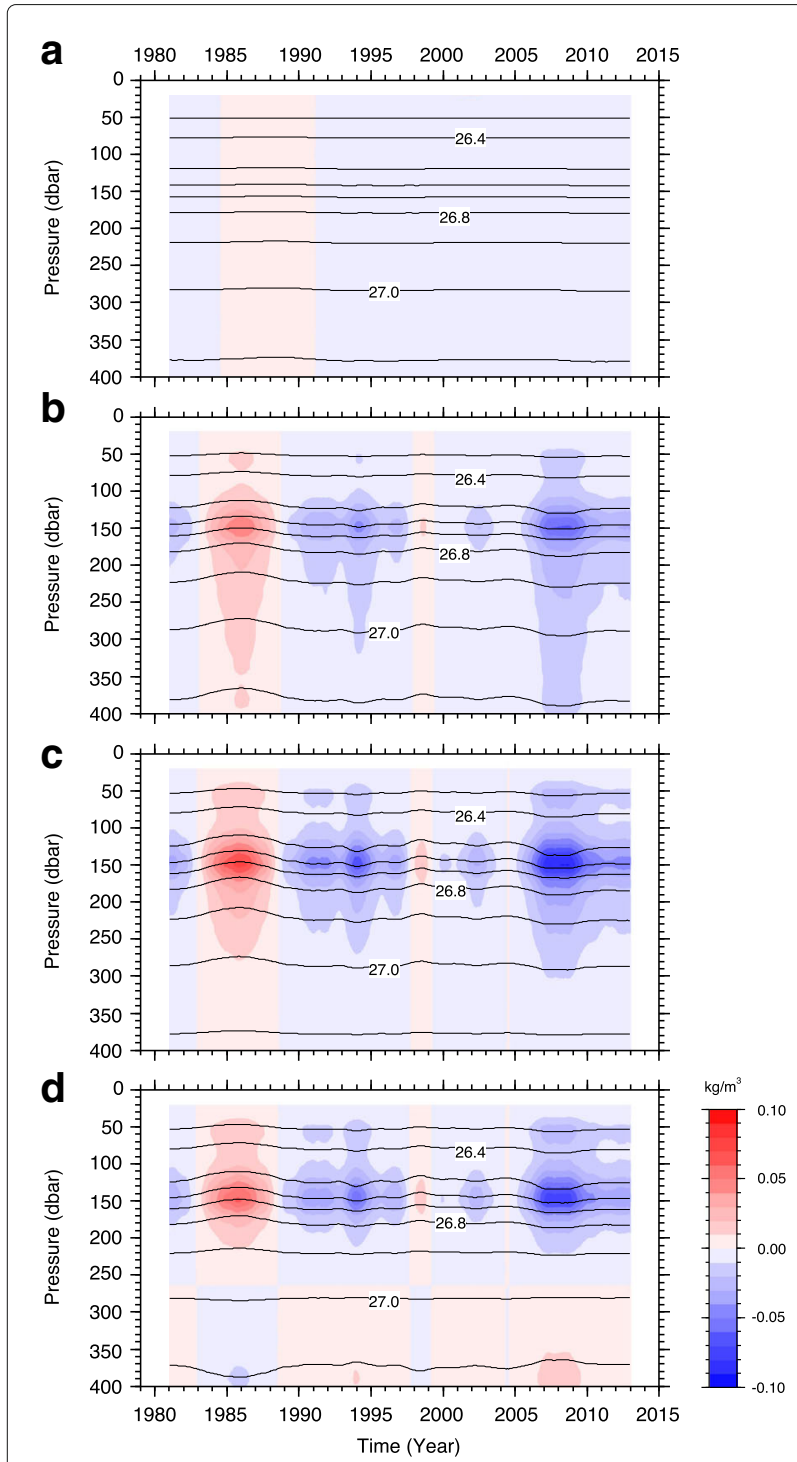

Fig. 18 Potential density $\left(\sigma_{\theta}\right.$, contours) and variations $\left(\mathrm{kg} \mathrm{m}^{-3}\right.$, color shades) in the top $400 \mathrm{dbar}$ layer due to the $\mathbf{a}$ first $(n=1)$, b second $(n=2)$, c third $(n=3)$, and $\mathbf{d}$ fourth $(n=4)$ baroclinic modes of the Rossby waves forced by the wind stress. The contour interval is $0.1 \mathrm{~kg} \mathrm{~m}^{-3}$. Smoothing was performed using a 49-month running mean filter

$(P)$ data, we calculated freshwater flux, $E-P$, as processed in Nagano et al. (2017). The vertical velocity due to freshwater flux estimated as $w_{\mathrm{F}}=(E-P) / \rho_{0}$ (e.g., Gill 1982) is downward owing to the excessive precipitation in the western subarctic region and its magnitude is approximately two orders smaller than that due to the wind stress. Although the downward velocity attenuated and acted to elevate SSH through the study period, the impact of the freshwater flux forcing on the SSH change is much less than that of the wind stress change.

\section{Conclusions}

Focusing on the wind stress changes in the subpolar North Pacific, we examined the interannual to decadal variations in SSH related to the northward shrinkage of the WSAG using a dynamical model of the Rossby waves forced by changes in the wind stress and damped by horizontal and vertical eddy dissipation. The Ekman vertical velocity derived from the NCEP/NCAR wind stress data during the period of 1979-2014 was decomposed into the four meridional modes of the sine functions. Assuming a flat bottom ocean, the eigenfunctions and eigenvalues of the four baroclinic Rossby wave modes were obtained by solving the vertical structure equation based on the potential density profile averaged between $160^{\circ} \mathrm{E}$ and $170^{\circ} \mathrm{E}$ at $47^{\circ} \mathrm{N}$ (WOCE P01 line). The SSH variations excited by changes in wind stress propagate with different phase speeds and damping rates depending on the meridional and baroclinic modes.

By adopting $D_{\mathrm{H}}=10 \mathrm{~m}^{2} \mathrm{~s}^{-1}$ and $B=1 \times 10^{-7} \mathrm{~m}^{2} \mathrm{~s}^{-3}$ for the horizontal and vertical eddy dissipation coefficients, respectively, we solved the vorticity gradient equation forced by the Ekman vertical velocity and obtained realistic SSH changes in the western subarctic region. SSH depressions related to the intensification of the Aleutian Low in winter of El Niño years, which were not comparably observed by the satellite altimetry, were produced probably because topographic effects such as the JEBAR were not taken into account in the model. With respect to the variations on decadal timescales, the correlation coefficient between the calculated and observed $\mathrm{SSH}$ variations is fairly high in the northwestern and eastern parts of the subpolar region; in particular, the value at K2 (0.79) exceeds the $90 \%$ confidence interval. However, probably because the damping parameters were set to be uniform in the whole subpolar region, the simulated SSH variation missed reproducing propagations of baroclinic SSH variations observed in the central subpolar North Pacific by the altimetry. The decadal SSH changes at $\mathrm{K} 2\left(47^{\circ} \mathrm{N}, 160^{\circ} \mathrm{E}\right)$ and $\mathrm{KNOT}\left(44^{\circ} \mathrm{N}, 155^{\circ} \mathrm{E}\right)$ associated with the northward gyre shrinkage was found to be primarily caused by the barotropic Rossby wave response to the relaxation of the Ekman suction due to the attenuation of the Aleutian Low by the frequent occurrences of La Niña after the late 1990s and the long-term weakening of the westerly wind. The northward WSAG shrinkage is found to be accompanied by the intensification of an anticyclonic circulation centered around $43-44^{\circ} \mathrm{N}, 170-175^{\circ} \mathrm{E}$ on the southeast of the WSAG. At the latitude of $\mathrm{K} 1\left(51^{\circ} \mathrm{N}\right)$, the $\mathrm{SSH}$ variation from the east of the southern end of the Aleutian Arc is shielded and that locally excited to the west affects the variation in $\mathrm{SSH}$ at $\mathrm{K} 1$.

The local baroclinic Rossby wave response to the weakening of the westerly wind was revealed to produce a decadal deepening of the upper main pycnocline in the 


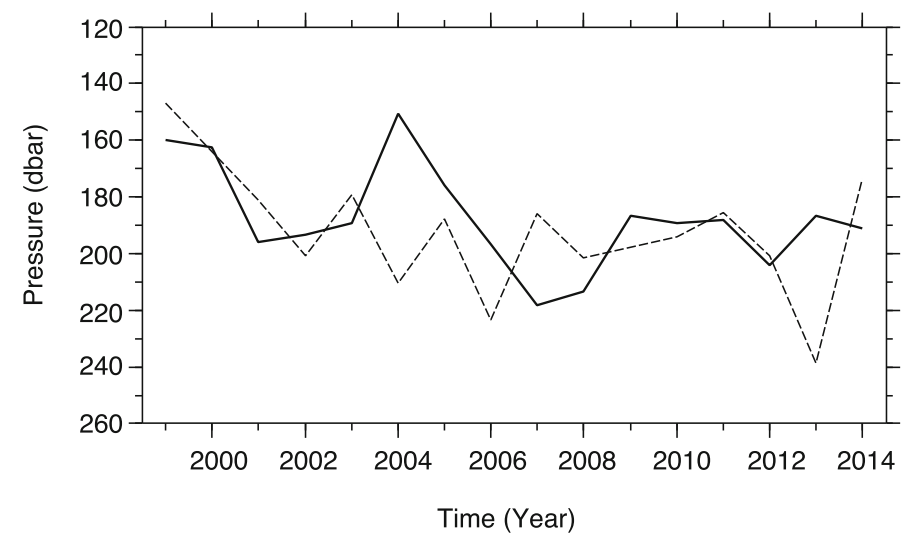

Fig. 19 Annual mean variations in the upper main pycnocline depth forced by variations in the wind stress (solid line) and the in situ halocline depth (dashed line) at station K2. The main pycnocline depth is indicated by the pressure level of the potential density of $26.8 \sigma_{\theta}$ and the halocline depth is the pressure level of the isohaline (33.8) estimated from the ship-board CTD and Argo data by Wakita et al. (2017)

western subarctic region. The disturbances of the first baroclinic Rossby wave mode propagated from the forcing regions and decayed substantially after excited. Meanwhile, the disturbances of the higher baroclinic modes, i.e., the second, third, and fourth modes, simultaneously occur with the forcing and are significantly reinforced through the quasi-resonant amplification (QRA) mechanism owing to their slow propagations, i.e., persistent characters, until the balance between the forcing and damping is achieved.

Because the higher baroclinic modes have steep vertical gradients in the modal structures of the potential density in the top 250 dbar layer, the variations of these modes primarily contribute to the deepening of the upper main pycnocline. The impact of the first baroclinic mode variation on the upper main pycnocline is negligibly small. The linear trend of the wind-driven deepening of the upper main pycnocline at K2 during the period of 1999$2014\left(1.36 \mathrm{~m} \mathrm{year}^{-1}\right)$ reached approximately $70 \%$ of the linear trend of the in situ halocline depth $\left(1.79 \mathrm{~m} \mathrm{year}^{-1}\right)$ estimated by the method of Wakita et al. (2017). The deepening of the upper main pycnocline was primarily accounted for by the baroclinic Rossby wave response to the decadal change in wind stress.

\section{Abbreviations \\ AGEM: Altimetry-based gravest empirical mode; AVISO: Archiving, Validation and Interpretation of Satellite Oceanographic; CTD: \\ Conductivity-temperature-depth; ENSO: El Niño-Southern Oscillation; JAMSTEC: Japan Agency for Marine-Earth Science and Technology; NCEP/NCAR: National Centers for Environmental Prediction/National Center for Atmospheric Research; NPI: North Pacific Index; PDO: Pacific Decadal Oscillation; QRA: Quasi-resonant amplification; SSH: Sea surface height; WOCE: World Ocean Circulation Experiment; WOD2013: World Ocean Database 2013; WSAG: Western subarctic gyre}

\section{Acknowledgements}

The authors thank Dr. M. Nonaka (JAMSTEC) and Dr. A. Kuwano-Yoshida (Kyoto University) for the helpful comments on the ENSO-timescale wind-driven SSH variation. The authors are also grateful to the editor, Prof. Akira Oka (Atmosphere and Ocean Research Institute, The University of Tokyo), and anonymous reviewers for constructive review comments.

\section{Authors' contributions}

AN proposed the topic, conceived, and designed the study. MW analyzed the data and collaborated with the corresponding author in the construction of the manuscript. Both authors read and approved the final manuscript.

\section{Funding}

This work was supported by Japan Society for the Promotion of Science (JSPS), Grant-in-Aid for Scientific Research (15H02835, 17K05660).

\section{Availability of data and materials}

The datasets supporting the conclusions of this article, i.e., the NCEP/NCAR forcing, WOCE P01 CTD, and altimetric SSH data, were provided by the US National Oceanic and Atmospheric Administration/Earth System Research Laboratory, Physical Sciences Division (http://www.esrl.noaa.gov/psd/), Clivar and Carbon Hydrographic Data Center (https://cchdo.ucsd.edu/cruise/ 49KA199905_1), and Copernicus Marine Environment Monitoring Service (http://marine.copernicus.eu), respectively.

\section{Competing interests}

The authors declare that they have no competing interest.

\section{Author details}

${ }^{1}$ Research Institute for Global Change, Japan Agency for Marine-Earth Science and Technology (JAMSTEC), 2-15 Natsushima-cho, Yokosuka Kanagawa 237-0061, Japan. ${ }^{2}$ Mutsu Institute for Oceanography, Japan Agency for Marine-Earth Science and Technology (JAMSTEC), 690 Kitasekine Sekine, Mutsu Aomori 035-0022, Japan.

Received: 21 October 2018 Accepted: 28 July 2019

Published online: 30 August 2019

\section{References}

Andreev A, Kusakabe M, Honda M, Murata A, Saito C (2002) Vertical fluxes of nutrients and carbon through the halocline in the western subarctic gyre calculated by mass balance. Deep-Sea Res II 49:5577-5593

AVISO (2016) SSALTO/DUACS user handbook: (M)SLA and (M)ADT near-real time and delayed time products. CLS-DOS-NT-06-034 - Issue 5.0 - Date: 2016/08/20 - Nomenclature: SALP-MU-P-EA-21065-CLS

Boyer TP, Antonov JI, Baranova OK, Coleman C, Garcia HE, Grodsky A, Johnson DR, Locarnini RA, Mishonov AV, O'Brien TD, Paver CR, Reagan JR, Seidov D, Smolyar IV, Zweng MM (2013) World Ocean Database 2013. https://doi.org/10.7289/N5NZ85MT 
Chelton DB, Schlax MG (1996) Global observations of oceanic Rossby waves. Science 272:234-238. https://doi.org/10.1126/science.272.5259.234

Coumou D, Petoukhov V, Rahmstorf S, Petri S, Schellnhuber HJ (2014) Quasi-resonant circulation regimes and hemispheric synchronization of extreme weather in boreal summer. Proc Natl Acad Sci USA 111(34):12331-12336. https://doi.org/10.1073/pnas.1412797111

Dodimead AJ, Favorite F, Hirano T (1963) Winter oceanographic conditions in the central Subarctic Pacific. Bull Int N Pac Comm 13:1-195

Enfield DB, Allen JS (1980) On the structure and dynamics of monthly mean sea level anomalies along the Pacific coast of North and South America. J Phys Oceanogr 10:557-578

Favorite F, Dodimead AJ, Nasu K (1976) Oceanography of the subarctic Pacific region. Bull Int N Pac Comm 33:1-187

Feldstein SB (2000) The timescale, power spectra, and climate noise properties of teleconnection patterns. J Clim 13:4430-4440

Frankignoul C, Müller P, Zorita E (1997) A simple model of the decadal response of the ocean to stochastic wind forcing. J Phys Oceanogr 27:1533-1546

Fukasawa M, Freeland H, Perkin R, Watanabe T, Uchida H, Nishina A (2004) Bottom water warming in the North Pacific Ocean. Nature 427:825-827. https://doi.org/10.1038/nature02337.

Gill AE (1982) Atmosphere-Ocean Dynamics. Academic Press, London. https:// doi.org/10.1002/qj.49711046322

Hu Z-Z, Kumar A, Huang B, Zhu J, Zhang R-H, Jin F-F (2017) Asymmetric evolution of El Niño and La Niña: the recharge/discharge processes and role of the off-equatorial sea surface height anomaly. Clim Dyn 49:2737-2748. https://doi.org/10.1007/s00382-016-3498-4

Ishi Y, Hanawa K (2005) Large-scale variabilities of wintertime wind stress curl field in the North Pacific and their relation to atmospheric teleconnection patterns. Geophys Res Lett 32(L10607). https://doi.org/10.1029/ 2004GL022330

Isoguchi O, Kawamura H, Kono T (1997) A study on wind-driven circulation in the subarctic North Pacific using TOPEX/POSEIDON altimeter data. J Geophys Res 102(C6):12457-12468

Isoguchi O, Kawamura H (2006) Seasonal to interannual variations of the western boundary current of the subarctic North Pacific by a combination of the altimeter and tide gauge sea levels. J Geophys Res 111(C04013). https://doi.org/10.1029/2005JC003080

Isoguchi O, Kawamura H, Oka E (2006) Quasi-stationary jets transporting surface warm waters across the transition zone between the subtropical and the subarctic gyres in the North Pacific. J Geophys Res 111(C10003). https://doi.org/10.1029/2005JC003402

Jacobs GA, Hurlburt HE, Kindle JC, Metzger EJ, Mitchell JL, Teague WJ, Wallcraft AJ (1994) Decade-scale trans-Pacific propagation and warming effects of an El Niño anomaly. Nature 370:360-363

Kalnay E, Kanamitsu M, Kistler R, Collins W, Deaven D, Gandin L, Iredell M, Saha S, White G, Woollen J, Zhu Y, Chelliah M, Ebisuzaki W, Higgins W, Janowiak J, Mo KC, Ropelewski C, Wang J, Leetmaa A, Reynolds R, Jenne R, Joseph D (1996) The NCEP/NCAR 40-year reanalysis project. Bull Am Meteorol Soc 77(3):437-471

Kawabe M (2000) Calculation of the interannual variations of sea level in the subtropical North Pacific. J Oceanogr 56:691-706

Kawabe M (2001) Interannual variations of sea level at Nansei Islands and volume transport of the Kuroshio due to wind changes. J Oceanogr 57:189-205

Kornhuber K, Petoukhov V, Petri S, Rahmstorf S, Coumou D (2017) Evidence for wave resonance as a key mechanism for generating high-amplitude quasi-stationary waves in boreal summer. Clim Dyn 49:1961-1979. https:// doi.org/10.1007/s00382-016-3399-6

Kuroda H, Wagawa T, Shimizu Y, Ito S, Kakehi S, Okunishi T, Ohno S, Kusaka A (2015) Interdecadal decrease of the Oyashio transport on the continental slope off the southeastern coast of Hokkaido, Japan. J Geophys Res 120(4):2504-2522. https://doi.org/10.1002/2014JC010402

LeBlond PH, Mysak LA (1978) Waves in the Ocean. Elsevier oceanography series, vol 20. Elsevier, Amsterdam

Le Provost C (2001) Ocean tides. In: Fu L-L, Cazenave A (eds). Satellite altimetry and earth sciences: a handbook for techniques and applications. Academic Press, London. pp 267-303. Chap. 6

Maharaj AM, Cipollini P, Holbrook NJ, Killworth PD, Blundell JR (2007) An evaluation of the classical and extended Rossby wave theories in explaining spectral estimates of the first few baroclinic modes in the South Pacific Ocean. Ocean Dynam 57:173-187. https://doi.org/10.1007/s10236006-0099-5
Mantua NJ, Hare SR, Zhang Y, Wallace JM, Francis RC (1997) A Pacific interdecadal climate oscillation with impacts on salmon production. Bull Amer Meteor Soc 78(78):1069-1079

Mantua NJ, Hare SR (2002) The Pacific Decadal Oscillation. J Oceanogr 58:35-44

Miura T, Suga T, Hanawa K (2002) Winter mixed layer and formation of dichothermal water in the Bering Sea. J Oceanogr 58:815-823

Nagata Y, Ohtani K, Kashiwai M (1992) Subarctic gyre in the North Pacific Ocean. Oceanogr Jpn 1(3):75-104

Nagano A, Wakita M, Watanabe S (2016) Dichothermal layer deepening in relation with halocline depth change associated with northward shrinkage of North Pacific western subarctic gyre in early 2000s. Ocean Dyn 66(2):163-172. https://doi.org/10.1007/s10236-015-0917-8

Nagano A, Hasegawa T, Ueki I, Ando K (2017) El Niño-Southern Oscillation-time scale covariation of sea surface salinity and freshwater flux in the western tropical and northern subtropical Pacific. Geophys Res Lett 44:6895-6903. https://doi.org/10.1002/2017GL073573

Ohba M, Ueda H (2009) Role of nonlinear atmospheric response to SST on the asymmetric transition process of ENSO. J Clim 22:177-192. https://doi.org/ 10.1175/2008JCLI2334.1

Ohtani K (1973) Oceanographic structure in the Bering Sea. Mem Fac Fish Hokkaido Univ 21:61-106

Pedlosky J (1987) Geophysical Fluid Dynamics, 2nd edn.. Springer, New York. https://doi.org/10.1007/978-1-4612-4650-3

Petoukhov V, Rahmstorf S, Petri S, Schellnhuber HJ (2013) Quasiresonant amplification of planetary waves and recent Northern Hemisphere weather extremes. Proc Natl Acad Sci USA 110(14):5336-5341. https://doi. org/10.1073/pnas.1222000110

Qiu B, Miao W, Müller P (1997) Propagation and decay of forced and free baroclinic Rossby waves in off-equatorial oceans. J Phys Oceanogr 27:2405-2417

Qiu B (2002) Large-scale variability in the midlatitude subtropical and subpolar North Pacific Ocean: observations and causes. J Phys Oceanogr 32:353-375

Rio MH, Guinehut S, Larnicol G (2011) New CNES-CLS09 global mean dynamic topography computed from the combination of GRACE data, altimetry, and in situ measurements. J Geophys Res 116(C07018). https://doi.org/10. 1029/2010JC006505

Ripa P (1978) Normal Rossby modes of a closed basin with topography. J Geophys Res 83(C4):1947-1957

Roden Gl (2000) Flow and water property structures between the Bering Sea and Fiji in the summer of 1993. J Geophys Res 105(C12):28595-28612

Schopf PS, Anderson DLT, Smith R (1981) Beta-dispersion of low-frequency Rossby waves. Dynam Atmos Ocean 5:187-214

Sekine Y (1999) Anomalous southward intrusions of the Oyashio east of Japan: 2. two-layer numerical model. J Geophys Res 104(C2):3049-3058. https:// doi.org/10.1029/1998JC900044

Sen PK (1968) Estimates of the regression coefficient based on Kendall's tau. J Am Stat Assoc 63(324):1379-1389

Stammer D (1998) On eddy characteristics, eddy transports, and mean flow properties. J Phys Oceanogr 28:727-739

Trenberth KE, Hurrel JW (1994) Decadal atmosphere-ocean variations in the Pacific. Clim Dynam 9:303-319

Tsurushima N, Nojiri Y, Imai K, Watanabe S (2002) Seasonal variations of carbon dioxide system and nutrients in the surface mixed layer at station KNOT $\left(44^{\circ} \mathrm{N}, 155^{\circ} \mathrm{E}\right)$ in the subarctic western North Pacific. Deep-Sea Res II 49:5377-5394

Wakita M, Watanabe S, Murata A, Tsurushima N, Honda M (2010) Decadal change of dissolved inorganic carbon in the subarctic western North Pacific Ocean. Tellus 62B:608-620. https://doi.org/10.1111/j.1600-0889. 2010.00476.x

Wakita M, Watanabe S, Honda M, Nagano A, Kimoto K, Matsumoto K, Kawakami H, Fujiki T, Kitamura M, Sasaoka K, Sasaki K, Nakano Y, Murata A (2013) Ocean acidification from 1997 to 2011 in the subarctic western North Pacific Ocean. Biogeosciences 10:7817-7827. https://doi.org/10. 5194/bg-10-7817-2013

Wakita M, Nagano A, Fujiki T, Watanabe S (2017) Slow acidification of the winter mixed layer in the subarctic western North Pacific. J Geophys Res 122:6923-6935. https://doi.org/10.1002/2017JC013002

Wallace JM, Gutzler DS (1981) Teleconnections in the geopotential height field during the Northern Hemisphere Winter. Mon Wea Rev 109:784-812

Watanabe YM, Ono T, Shimamoto A, Sugimoto T, Wakita M, Watanabe S (2001) Probability of a reduction in the formation rate of the subsurface water in 
the North Pacific during the 1980s and 1990s. Geophys Res Lett 28(17):3289-3292. https://doi.org/10.1029/2001GL013212

Wilks DS (2019) Statistical methods in the atmospheric sciences, 4th edn.

Elsevier, Amsterdam. https://doi.org/10.1016/C2017-0-03921-6

\section{Publisher's Note}

Springer Nature remains neutral with regard to jurisdictional claims in published maps and institutional affiliations.

\section{Submit your manuscript to a SpringerOpen ${ }^{\circ}$} journal and benefit from:

- Convenient online submission

- Rigorous peer review

- Open access: articles freely available online

- High visibility within the field

- Retaining the copyright to your article

Submit your next manuscript at $\gg$ springeropen.com 